\title{
Fragmentos para armar un territorio. La textilería en Atacama durante los períodos Intermedio Tardío y Tardío
}

Carolina Agüero P. ${ }^{1}$

\section{RESUMEN}

Este estudio se enmarca dentro de los lineamientos del proyecto FONDECYT 1000148 "Historia cultural y materialidad en la arqueología de los períodos Intermedio Tardío y Tardío de San Pedro de Atacama y su relación con la cuenca del río Loa", que intenta someter a análisis las fases Yaye, Solor y Catarpe definidas para el Salar. En nuestro caso esto se realizará a través de estudios sistemáticos de materiales textiles de colecciones, para contrastar sus expresiones con los procesos detectados a lo largo del Loa, teniendo en consideración el supuesto de que estas dos cuencas formaron parte -durante los períodos mencionados- de un territorio culturalmente compartido. En esa dirección, a partir de la revisión exhaustiva de las notas de Le Paige, y el estudio de las colecciones funerarias tardías del Museo Arqueológico $R$. P. Gustavo Le Paige s. j., proponemos una secuencia preliminar de la textilería en los oasis de San Pedro de Atacama durante los períodos Intermedio Tardio y Tardío, y la integramos en la secuencia textil regional. A raíz de este procedimiento surgen cuestionamientos sobre las fases antes mencionadas.

Palabras claves: textiles - Atacama - Período Intermedio Tardío.

\section{ABSTRACT}

This paper is set within the outlines of the research project "Cultural history and materiality in the archaeology of Late Intermediate and Late periods of San Pedro de Atacama and its relation with the Loa basin" which aims to analyze the Yaye, Solor and Catarpe phases. In our case, this will be achieved by means of systematic studies of textile collections in order to compare its expressions with processes detected along the Loa River, considering that both basins were part of a culturally shared territory. Through an accurate review of Le Paige's manuscripts and the study of late funerary collections from the G. Le Paige Archaeological Museum, we propose a preliminary textile sequence for the San Pedro de Atacama oasis during the Late Intermediate and Late periods, and its integration into the regional textile sequence. As a result of these proceedings, questions about the mentioned phases were raised.

Key words: textiles - Atacama - Late Intermediate Period.

1 Instituto de Investigaciones Arqueológicas y Museo R. P. Gustavo Le Paige s. j., Universidad Católica del Norte, San Pedro de Atacama. Email: maguero@ucn.cl

\section{Introducción}

El uso generalizado de tejidos para la vestimenta $\mathrm{y}$ otros artefactos por parte de las poblaciones atacameñas, los ha convertido en una valiosa fuente de información dentro del registro arqueológico de la región. No obstante su potencialidad, han sido pocos los estudios en los que se ha explotado esta veta. Entre estos se encuentran los trabajos de Latcham (1938) para parte de este territorio, las descripciones de tejidos de Calama realizadas por Oyarzún (1931), el análisis de materiales de varios sitios de Quitor que hiciera Lindberg (1960, 1964), las descripciones de textiles de Chiu Chiu efectuadas por Rydén (1944) y Mostny (1956), y los trabajos de Benavente (1982) para ese mismo oasis. Posteriormente, Oakland (1992, 1994) retoma esta importante línea de investigación y se centra en el Período Medio de San Pedro, ya con un tipo de aproximación más sistemática en lo que se refiere al análisis textil. Luego, es Tarragó (1989) quien integra información textil en su periodificación de la prehistoria del Salar, y de acuerdo a la observación de los contextos funerarios de San Pedro de Atacama reali$\mathrm{za}$, aunque breve, la primera secuencia textil para los oasis (Figura 1). Observa que los gorros afelpados tipo boina con dos orejas y la técnica de tramas y urdimbres discontinuas se asocian a contextos del Negro Pulido y Tiwanaku, y que las túnicas largas asociadas a collares de ignembrita y gorros de piel con corona de paja trenzada se relacionan a contextos tardíos. Otras prendas como los bonetes de Catarpe y los turbantes de tela de Solcor se relacionan a alfarería Roja Violácea. Así mismo nota que las túnicas con listas laterales de color concho de vino se asocian al Rojo Violáceo. Finalmente, el desarrollo de investigaciones arqueológicas en los últimos años en la localidad de Quillagua (Loa Inferior) permitió reconocer en los depósitos funerarios la existencia de textiles que expresaban un comportamiento estilístico característico para la región cultural de Atacama durante el Período Intermedio Tardío (900-1450 DC; Agüero et al. 1997 y 1999, Agüero 1998). 


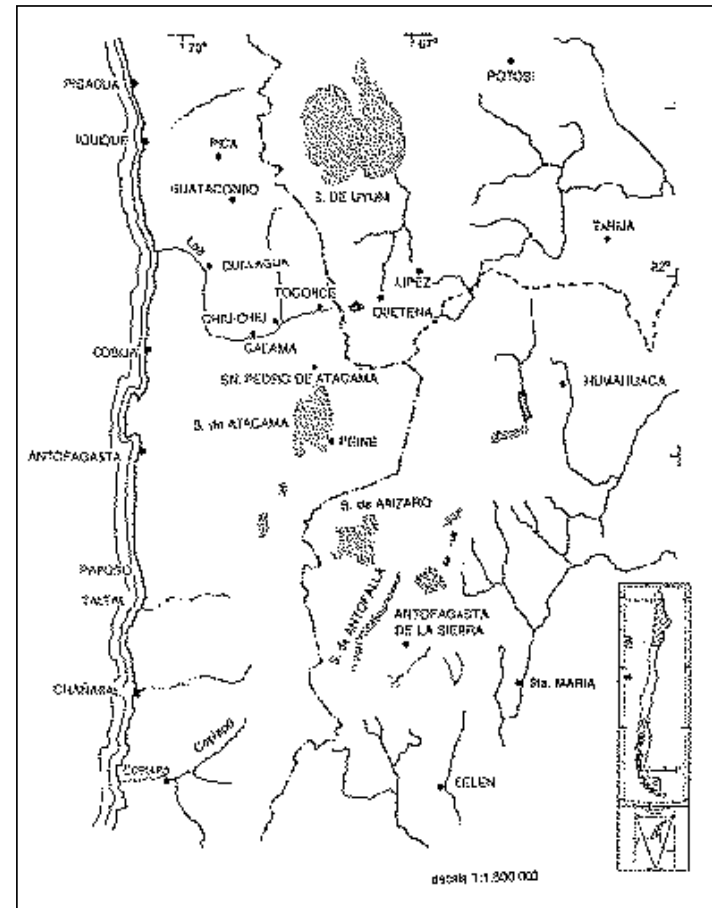

Figura 1. Mapa de la Subárea Circumpuneña, en la cual San Pedro de Atacama se localiza al norte del Salar de Atacama.

De acuerdo a lo anterior, dentro de este estilo atacameño, el análisis principalmente de túnicas del Período Intermedio Tardío Inicial de San Pedro (correspondiente a la Fase Yaye), y Chiu Chiu en el Loa Medio, se identificó la existencia de un grupo textil netamente "san pedrino" -en el que se integraban los grupos A y B de Oakland (1992)-, y el que estaba bien representado en el Cementerio Poniente de Quillagua (Qui-03) en asociación a cerámica Dupont y a una fecha de 980 DC. Este grupo lo integraban túnicas rectangulares con decoración bordada en puntada satín en las uniones laterales, abertura de brazos, cuello y orillas de urdimbre, realizando motivos de volutas, ganchos, zigzags, cruces y escalerados. El uso de tramas múltiples y los bordados laterales son elementos invariables en estas prendas. Luego, en los cementerios Oriente y Oriente Alto de Quillagua (Qui-01 y 02) resultaron ser frecuentes prendas que eran estructuralmente como las anteriores, pero que más bien correspondían a algunos de los tipos identificados por Oakland en sitios del Período Medio, como Coyo Oriente y Solcor-3. Allí aparecían junto a alfarería Roja Violácea, en cambio, en los contextos de Quillagua se asociaban a alfarería Ayquina, Dupont, Rojo
Burdo y Rojo Violáceo y a textiles y alfarería tarapaqueña (Chiza, Pica-Charcollo) relacionada con el oasis de Pica, mezclándose en ellos muchas veces los atributos de los componentes atacameño y tarapaqueño. Las fechas (980-1110 DC) y las asociaciones asignaban este momento a la Fase Solor del Salar. Finalmente, se observó en Qui-03 (1370-1480 DC), en Lasana y Calama en el Loa Medio, en la desembocadura del mismo río y en contextos de finales del Intermedio Tardío del Noroeste Argentino -como los del Pucara de Tilcara, Tastil, Doncellas y Sayate (Boman 1908, Rolandi de Perrot 1973 y 1979, Pelissero et al. 1997, Renard 1997)- a un grupo de prendas rectangulares, principalmente túnicas y bolsas, que utilizan las técnicas decorativas de urdimbres transpuestas y uso de tramas múltiples, y de tapicería dentada (dovetailed), hilados de colores blanco, azul y rojo con los que reproducen motivos de "V" o rombos en sucesión vertical -en el caso de la transposición de urdimbres- y cuadrados, y en el caso de la tapicería a una característica figura zoomorfa de tres dedos. Su distribución geográfica y la utilización de cinco tramas alternadas nos permitieron insertarlas dentro del componente atacameño -aun cuando no las habíamos registrado en los oasis de San Pedro-, así como los contextos en que aparecían las situaban hacia los finales del Intermedio Tardío, extendiéndose espacialmente hacia al sur, a Calingasta (Michieli 1994), y temporalmente, incluso, hasta la llegada del Inca, como lo indican piezas atacameñas trasladadas hacia el norte y encontradas en Camarones-9 (Ulloa, com. pers. 1998) y Azapa-8. Los vínculos con la puna argentina unida a esta situación "expansiva" de la población atacameña, nos condujo a asignar a estos tejidos a la Fase Turi (1390-1450 DC; Agüero et al. 1997 y 1999), la cual estaría dando cuenta de un momento en que se deja sentir en parte del territorio atacameño una significativa influencia de las poblaciones del altiplano meridional a través de las del Loa Superior, región en la cual fue identificada originalmente (Aldunate 1993).

Sin embargo, aun cuando en esta secuencia estaban integradas la cuenca del Loa Medio e Inferior y el Noroeste de Argentina, la textilería del núcleo del territorio atacameño -San Pedro de Atacama- estaba solamente representada por materiales de un sitio de la Fase Yaye, Solor-3 (Agüero 1998), habiendo un vacío de información para 
el resto del período. De acuerdo a lo anterior, una de las tareas principales era entonces estudiar las colecciones procedentes de los sitios funerarios Yaye, Solor y Catarpe que han sido considerados los yacimientos-tipo de las fases tardías de la prehistoria del Salar (Figura 2).

Hay que mencionar que algunas de las causas que parecen haber influenciado cierto desinterés en su estudio es el saqueo intensivo de los cementerios, así como el hecho de que los contextos del Intermedio Tardío del Salar son menos abundantes que los del Período Medio. Además, ya cuando Le Paige trabajó la mayoría de los sitios mencionados, su cercanía al curso del río Vilama (sitios Vilama, Solor-3 y Solor-4) y al del río San Pedro (sitios Yaye, Coyo-3) había causado la destrucción casi completa de los materiales más frágiles de los contextos, como los textiles. En parte, esta situación se evitó en Solor-3, donde se habrían conservado tejidos y gorros de piel por estar en un piso más elevado, al igual que en Catarpe-2 que se ubica sobre la terraza Este del río San Pedro. No obstan- te, las cuidadosas notas de campo que Le Paige tomaba (1957 en adelante) nos ayudaron a saber más sobre la textilería de los períodos Intermedio Tardío y Tardío en los oasis de San Pedro de Atacama, para lo cual también hay que considerar que él no ponía demasiada atención en estos materiales, sino en la cerámica, las maderas y los metales, siendo lo más probable que el número de tejidos haya sido mayor a lo que anotara. Por otro lado, hay que tener en cuenta que el registro de Le Paige tampoco es exacto, pues nosotros pudimos examinar tejidos que él no había consignado en sus notas de campo. Todo lo anterior ha llevado a una deficiente conservación y documentación de estos contextos en general.

En las siguientes páginas intentaremos superar esta situación de manera de lograr una caracterización cualitativa y cultural de los textiles de los momentos tardíos de la prehistoria del Salar de Atacama, identificando los indicadores cronológicos que nos permitan integrarlos -y así complementar- a la secuencia textil regional.

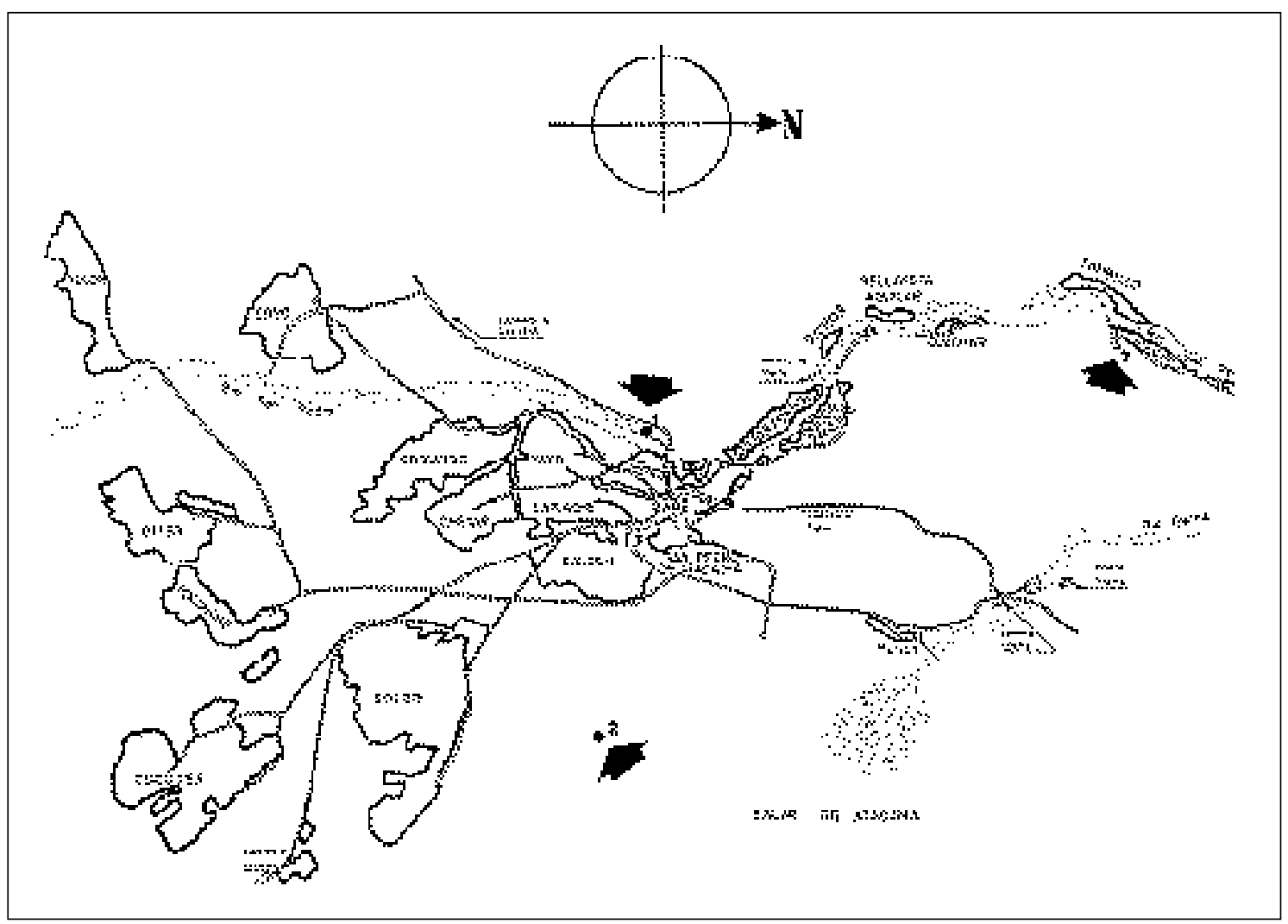

Figura 2. Ubicación de los sitios 1) Yaye, 2) Campos de Solor y 3) Catarpe en el mapa de San Pedro de Atacama. 


\section{Los textiles de los períodos Intermedio} Tardío y Tardío del Salar de Atacama

A continuación revisaremos la información sobre la textilería del Período Intermedio Tardío de San Pedro de Atacama recopilada tanto en fuentes bibliográficas constituidas principalmente por las notas de campo y fotografías de Le Paige, como a través del registro de colecciones arqueológicas. Organizaremos esta revisión de acuerdo al orden cronológico-cultural propuesto por Tarragó (1989).

Siguiendo su periodificación, para los momentos tardíos que nos interesan, se tendría una Fase Yaye (950-1200 DC) correspondiente a un momento transicional en el que ha terminado la influencia de Tiwanaku, iniciándose una reorganización de la cultura local en la que empiezan a ser característicos los gorros "tipo corona", las calabazas, tejnes y los collares de grandes cuentas de liparita en contextos catalogados de "pobres", también con escasa presencia de escudillas Dupont y Ayquina, indicadores de una transición desde los finales del Período Medio. Luego seguiría la Fase Solor (1200-1470 DC), la cual describe un momento de pleno desarrollo de la cultura local. Los sitios habitacionales integran en ellos a entierros cuyos contextos están caracterizados por alfarería Rojo Violácea, urnas Solcor-Solor y foránea, como Yavi, Yura-Huruquilla y Hedionda, dando cuenta de un incremento las relaciones interregionales. Finalmente se desarrollaría la Fase Catarpe que integra la presencia inca en los oasis de Atacama hasta la llegada de los españoles. Algunos de los sitios que muestran esta presencia son Catarpe-1, Solor Ayllu, Hostería y los santuarios de altura volcán Licancabur, cerro Pili y Quimal.

1.- Fase VI o Yaye (950-1200 DC). Está caracterizada por contextos de los sitios funerarios Yaye 1, 2, 3 y 4 (Le Paige 1964 Ms, 1977 Ms), Solor3 piso superior del Túmulo Norte (Le Paige 195758 Ms), Coyo-3 (Costa y Llagostera 1994) y Quitor-9 (Le Paige 1963 Ms), los que han sido descritos como "pobres" debido a la ausencia de ajuar, o bien, a los pocos objetos que lo componen. Esto además se debe, en parte, a que los cementerios de Yaye y Coyo-3 -situados en espacios diferentes a aquellos con ocupación del Período Medio- se encontraban emplazados en lugares bajos cercanos al antiguo lecho del río San Pedro, cuya humedad y crecidas afectaron negati- vamente los materiales orgánicos más frágiles, como la cestería y los textiles. Afortunadamente para nosotros, este hecho se evitó en parte en Solor-3, que por estar más elevado (en el piso superior del túmulo), estos materiales aún se conservan.

Yaye 1, Yaye 2, Yaye 3 y Yaye 4 . A poca distancia del río San Pedro, en Yaye, Le Paige (1964 Ms, 1977 Ms) reporta la existencia de cuatro cementerios. En ellos, las tumbas estaban indicadas por un palo vertical y los cuerpos en cuclillas depositados en pozos cavados a una profundidad de 1 a $1.50 \mathrm{~m}$. Los contextos corresponderían "a la tercera fase del Agroalfarero atacameño", porque si bien algunos individuos exhumados todavía tenían algunos elementos del Período Medio en sus ajuares, los cementerios mostraban total ausencia de alfarería San Pedro Negro Pulida. De los cuatro cementerios, Le Paige recupera 170 tumbas de las que aproximadamente la mitad no tenía ajuar, situación que lo lleva a afirmar que son "de los más pobres que hay". Debido a la similitud existente entre ellos, trataremos a los cuatro cementerios de Yaye como una unidad. Lamentablemente no se han conservado los textiles, por lo que es primordial revisar los apuntes del padre Le Paige (1964 Ms, 1977 Ms) quien describe aproximadamente 39 de estos artefactos entre los que destacan los gorros de piel:

a) a los que les queda la corona de paja "de una torsada", "de tres torsadas", o bien, "quedan seis cordeles vegetales (paja) que componían la corona de paja, "queda la trenza de paja", "una sola trenza", "gruesa trenza" o "dos trenzas de paja" de la corona, que puede ser "fina y alta". Algunos tienen la piel teñida de rojo, otros alternando rojo y natural; uno en que "la piel no está teñida, centro tejido lindo dibujado". Le Paige anotó un total de 26 gorros de este tipo.

b) cuatro bolsas entre las que se cuentan una fina de varios colores (destruida), otra gruesa de lanas celeste y roja conteniendo "tableta para rapé sencilla con incrustación de perlas, tubo para aspirar rapé, una espátula de hueso, una espátula-cucharita, calabazas" y otros; bolsitas "amuletos" con semillas de algarrobo, y sin nada.

c) una túnica descrita como "pedazo de tejido (cotón) sobre la cabeza". 
d) restos de otros tejidos sin identificar: "queda pedazo de tejido fino bordado" o "pedazos de tejidos finos".

Coyo 3. Este cementerio situado al oeste del actual ayllu de Coyo, cerca del antiguo cauce del río San Pedro, fue excavado por Costa y Llagostera (1994) y cuenta con una fecha promedio de 930 DC. De aquí, se recuperaron 80 individuos enterrados en fosas cavadas directamente en la arena, y en cuyos ajuares -por problemas de conservación- los textiles, cestería y madera están pobremente representados. No obstante, los autores resaltan que, aun considerando esta variable, las ofrendas no son muy numerosas. El único objeto textil recuperado es un gorro de piel, que, lamentablemente, no se conserva (Costa y Llagostera, com. pers. 2001).

Quitor-9. Sus 23 tumbas en pozos marcadas con palos se ubicaron sobre la meseta al oeste del río San Pedro. Los contextos -algunos con asociaciones altiplánicas (cerámica Yura-Huruquilla)- indican a Le Paige (1963 Ms) que "se trata de la primera parte de la tercera fase del Agroalfarero de San Pedro de Atacama, anterior a la época de los entierros en urnas y de la desaparición del gorro", suposición que es confirmada por un fechado de $1050 \pm 80$ DC (Tarragó 1989: 357). Entre los textiles, Le Paige (1963 Ms) logra identificar siete:

a) cuatro gorros de piel, uno "con una trenza de paja" y tres con corona de paja trenzada en forma plana.

b) una bolsa de tejido fino y otra gruesa conteniendo tableta y tubos.

c) tejidos n/i: "varios con dibujos".

Solor-3 (piso superior del Túmulo Norte). Aunque Solor-3 ha sido usualmente entendido como exponente del Período Medio en San Pedro de Atacama (Le Paige 1957-58-59 Ms), en una publicación anterior (Agüero 1998) hacíamos notar que en el nivel superior del Túmulo Norte, las tumbas marcadas por postes, con fardos de individuos en cuclillas vestidos con túnicas, taparrabos sujetos por fajas y escasas ofrendas compuestas por patas de camélidos, tejnes, pocos ejemplares de cerámica Gris Alisada ("alfarería común, no "concho de vino"'), arcos y flechas, collares de liparita, calabazas y "saquitos-amuletos" lle- varon a Le Paige (1958 Ms) a afirmar que corresponden a "lo característico de la primera parte de la tercera fase del Agroalfarero de San Pedro de Atacama" (1964: 57). Le Paige (1957-58-59 Ms) describe para un total aproximado de 35 individuos enterrados aquí, 97 artefactos textiles de los cuales encontramos 24 en los depósitos del Museo de San Pedro:

a) un total de 17 gorros de piel de guanaco con centro tejido "sin dibujar" y otros "dibujados"; de piel sin fondo tejido; de piel teñida de rosado o rojo o "natural y rojo", "con centro dibujado" o "con centro dibujado y plumas de parina"; "con fondo tejido con dibujos escalonados"; y restos de coronas de paja. De éstos, sobre una momia registramos un gorro realizado con un torzal de paja y recubierto en piel de guanaco sin teñir. De todos ellos fue posible encontrar dos: aquel "con fondo tejido con dibujos escalonados" perteneciente a una momia de guagua indicada con el $\mathrm{n}^{\circ} 29$. Se conserva sólo una mitad de la parte tejida en anillado sencillo, en tanto ha desaparecido la corona de paja y piel. El diseño consiste en rombos escalonados bipartitos verticalmente en café claro/café oscuro, y destaca la torsión inversa (2SZ) de los hilados; y un segundo gorro de una sola pieza de piel teñida de rosado.

b) dos gorros afelpados descritos como "de terciopelo", uno "café con orejas" (publicado por Berenguer 1993: 30, fig. 3) y otro "café oscuro de forma cónica".

c) dos bonetes, uno tejido de forma hemisférica (Figura 3), y otro "en forma de cono con dibujos escalonados con tres o cuatro rectángulos de colores diferentes en cada cuadro, blanco, amarillo, verde, azul, colorado, café".

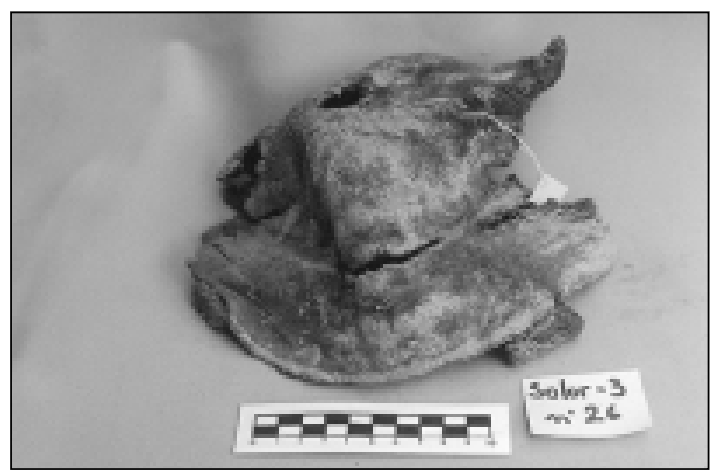

Figura 3. Bonete hemisférico afelpado de Solor-3. 
d) 27 túnicas, ya sean "fina con dibujos", "con dibujos de hilos de colores (verde café, blanco)", "con dibujos carmín y azul", "con dibujos en lanas de colores alrededor de abertura de cuello y brazo", "de 1.10 x 0.75 café oscura con muchas trenzas pequeñitas", "negra con listas de colores carmín y azul a los lados donde cosieron la pieza", "con bordes dibujados". De éstas, pudimos observar en las momias 18 ejemplares que coincidían con las anotaciones del padre y que se distribuían en tres tipos ya definidos (Agüero 1998). Todas, de forma cuadrada o rectangular, fueron confeccionadas en ligamento faz de urdimbre con hilados 2Z-S de color beige. En todos los ejemplares se registró la utilización de cinco tramas alternadas. El Tipo 1 mostraba las uniones laterales, aberturas para brazos y cuello y orillas de urdimbre bordadas en puntada satín en colores blanco, azul, rojo y amarillo ocre, con motivos de "ojos" y zigzags; en las tres primeras se realizó una franja de $1.5 \mathrm{~cm}$ de ancho con prolongaciones a distancias regulares en forma de "abanico". En ocasiones lleva una lista roja de $3.5 \mathrm{~cm}$ de ancho adyacente al espacio bordado. Por su parte, las orillas de urdimbre también llevan un bordado en puntada satín, pero sin prolongaciones, con motivos de ganchos y zigzags escalonados. El vértice de la abertura para el cuello se reforzó con un rectángulo realizado en puntada satín con motivos geométricos rectos o curvilíneos, en blanco, azul y rojo. El Tipo 2 también lleva en las uniones laterales y aberturas para brazos una franja de $1.5 \mathrm{~cm}$ bordada en puntada satín en colores azul y rojo (en puntadas e hilados más gruesas que en el Tipo 1) logrando motivos de rombos y "ojos"; también en ocasiones lleva una lista roja de $3.5 \mathrm{~cm}$ de ancho adyacente al espacio bordado. El vértice del cuello también está reforzado en puntada satín en rojo y azul, y los motivos varían en todos los individuos. No se observaron bordados ni en la abertura para el cuello ni en las orillas de urdimbre. Finalmente, el Tipo 3 presenta una lista a cada lado, roja en cinco ocasiones y concho de vino en una, y las uniones están cosidas con un encandelillado. Las aberturas no llevan terminaciones o bien, terminan en un festón anillado sencillo de color café oscuro (Figura 4).

e) 40 bolsas entre las que predominan los llamados "saquitos-amuletos" o "bolsitas-amuletos", habiendo también un saco y algunas bolsas "filet" en azul y rojo. De estas bolsas, durante el proceso de registro de colecciones encontramos tres

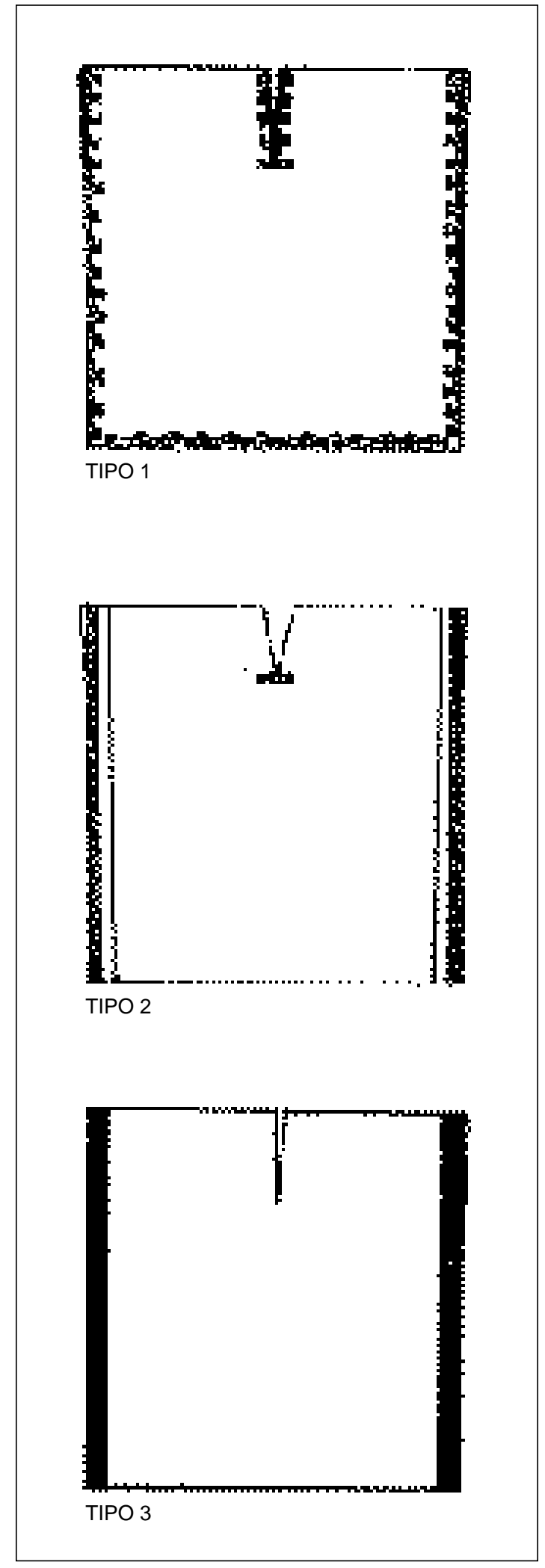

Figura 4. Tipos de túnicas de Solor-3 (tomado de Agüero 1998). 
"saquitos-amuletos", una de aquellas llamadas "filet" por Le Paige, y otra bolsa propiamente tal. Así, pudimos determinar que las primeras corresponden a pequeñas bolsitas de entre 4 a $8 \mathrm{~cm}$ de ancho x 6 a $10 \mathrm{~cm}$ de largo confeccionadas con restos de otros tejidos. Están cerradas y las costuras son encandelilladas de manera descuidada. En este caso, contenían semillas de algarrobo. Las segundas corresponden a un tejido alargado en técnica de sprang (Emery 1981, Frame 1986) o torzal oblicuo doble en el que los elementos funcionan en pares y se tuercen continuamente sobre ambas diagonales, resultando ambas caras idénticas. Se han utilizado hilados de colores azul, rojo, café y/o amarillo, que debido al enlace, evolucionan en forma oblicua, generando motivos romboidales creando un efecto "escocés". A unos $5 \mathrm{~cm}$ de las "asas" el tejido se fija por una pasada de tramas en torzal, a partir de donde se tejen los hilados en faz de urdimbre en listas lisas, para luego volver a separar los manojos que se enlazan a cuerdas de amarra. La tercera se trata de una bolsa de $10 \mathrm{~cm}$ de ancho x $16 \mathrm{~cm}$ de largo listada en colores naturales con las uniones cosidas en festón simple y la abertura cerrada con un encandelillado. Está contenida al interior de la segunda (Figura 5). f) una faja.

g) dos hondas.

h) una "pelota de hilos de colores verde, café, blanco".

i) tejidos $n / i$.

Hasta aquí, es notorio el grave problema de muestra con que nos enfrentamos ya que encontramos sólo un $15.9 \%$ de los textiles que observó Le Paige. De esta manera, de la lectura de sus notas se desprende que las prendas más representadas serían los gorros de piel (33\%) y las bolsas (32\%), seguidas de las túnicas (19.4\%). Nuestra cuenta de Solor-3 indica que, al contrario, serían las túnicas seguidas por las bolsas y los gorros, pero también hay que considerar que las túnicas se han conservado puestas en las momias, y que los otros objetos son "desmontables" de los contextos pudiendo, por ese motivo, haberse extraviado. Aun así, deberemos basarnos en ambas fuentes, puesto que no disponemos de más y mejores datos, teniendo siempre en consideración que toda esta información hay que tomarla con cautela.

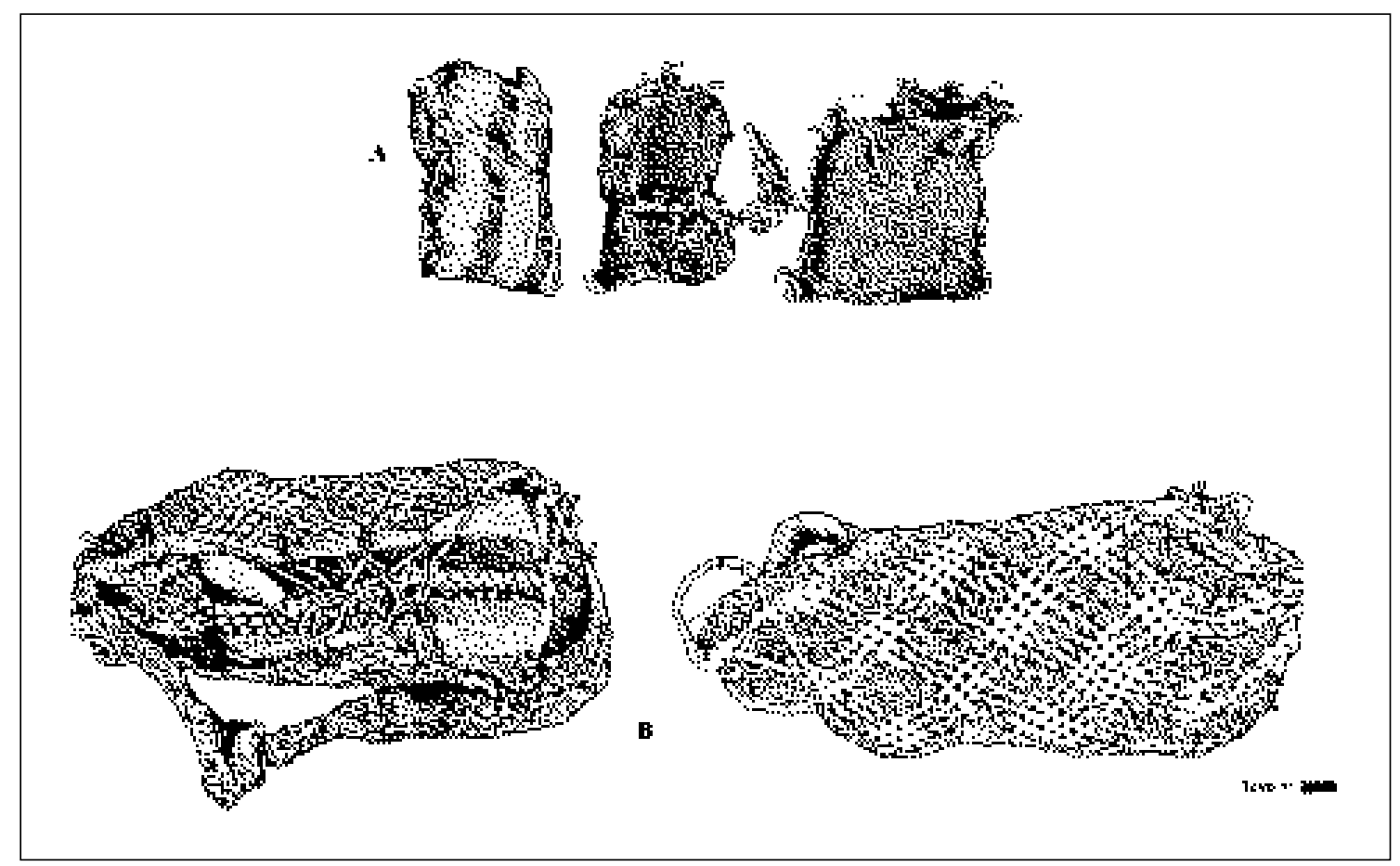

Figura 5. Bolsas de Solor-3. A) "saquitos-amuletos", B) bolsa tipo hamaca tejida en torzal oblicuo doble. En su interior contiene otra bolsa. 
Como bien observó Tarragó (1989), los gorros de piel empiezan a ser frecuentes en los contextos del Intermedio Tardío de los oasis de San Pedro, ya que todos los sitios tienen registrado al menos uno (Cuadro 1). Estos tienen la estructura de paja en forma de corona realizada de variadas maneras pudiendo hacerlo con un torzal grueso, con tres o hasta seis torzales en sucesión vertical; con una trenza gruesa, dos trenzas en sucesión vertical, o bien con un trenzado plano que crea estructuras altas y delgadas. Esta estructura va recubierta en piel de guanaco que puede ser una gran pieza de cuero, o bien, tiras de piel que enrollan la estructura tal como lo observó Tarragó (1989). La primera opción habría producido piezas monocromas (teñidas de rojo o sin teñir) y la segunda daba la posibilidad de alternar espacios rojos y naturales. Al parecer, la mayoría de estos gorros habrían sido sin casquete, pero en el caso de tener, éste se tejió de un solo color, y en siete casos con motivos de rombos escalonados en colores naturales y rojo, realizados en anillado sencillo; y en pocos, se distinguió la presencia de un penacho de plumas de parina (Figura 6).

Dos tipos más de gorros han sido descritos para Solor-3: los afelpados de color café oscuro entre los que destaca uno con orejas, y los bonetes, ambos muy escasamente representados. Al parecer, los gorros afelpados, según la descripción de Le Paige como "gorros de terciopelo bajos decorados" parecen corresponder a los gorros "tipo boina" (MChAP 1988, Iriarte y Renard 1998) registrados únicamente en San Pedro de Atacama y Loa Medio-Inferior. El bonete, según los dibujos de Le Paige, parece ser un gorro tejido en anillado de forma hemisférica o de cono, en cuyo caso muestra motivos escalonados de colores artificiales.

Luego, las túnicas registradas por nosotros coinciden bastante bien con las descripciones de Le Paige, ya que presentan decoración bordada en las orillas y una lista adyacente a las orillas de trama. Se observó uniformidad de atributos formales, tecnológicos y decorativos generales. En efecto, son todas de formas cuadradas o rectangulares de color beige ocre con lista lateral roja (un caso concho de vino, un caso sin lista) y bordado en puntada satín en las uniones laterales, abertura de cuello, brazos y refuerzo del vértice del cuello. Las orillas de urdimbre van terminadas en bordados en puntada satín y/o un festón anillado sencillo, y las tramas en todos los casos son múltiples. En la urdimbre las torsiones son fuertes, y flojas en las tramas, en tanto los hilados de la urdimbre presentan títulos muy altos, y los de la trama sólo altos. Del mismo modo, los motivos no del todo rectilíneos pero tampoco curvos, son bastante uniformes y entre ellos se cuentan ganchos, escalerados y "ojos". La densidad de urdimbre y trama casi no varía, siendo de 26 a $28 / 1$ y 8 a 9/1, respectivamente. En general hay poca diversidad de tipos y entre estos existe un indiscutible "aire de familia". Probablemente, cuando Le Paige se refiere a restos de "tejidos finos" en Yaye, se haya tratado de estas túnicas.

\begin{tabular}{|l|c|c|c|c|c|c|c|c|c|}
\hline \multirow{2}{*}{ SITIO } & \multicolumn{2}{|c|}{ YAYE } & \multicolumn{2}{c|}{ COYO-3 } & \multicolumn{2}{c|}{ QUITOR-9 } & \multicolumn{2}{c|}{ SOLOR-3 } & \multirow{2}{*}{ Total Le Paige } \\
\cline { 1 - 6 } PRENDA/ REGISTRO & Le Paige & $\mathbf{2 0 0 0}$ & Le Paige & $\mathbf{2 0 0 0}$ & Le Paige & $\mathbf{2 0 0 0}$ & Le Paige & $\mathbf{2 0 0 0}$ & \\
\hline Gorros piel & 26 & - & 1 & - & 4 & - & 17 & 2 & 48 \\
Gorros afelpados & - & - & - & - & - & - & 2 & - & 2 \\
Bonetes & - & - & - & - & - & - & 2 & - & 2 \\
Turbantes de tela & - & - & - & - & - & - & - & - & - \\
Túnicas & 1 & - & - & - & - & - & 27 & 18 & 28 \\
Mantas & - & - & - & - & - & - & - & - & - \\
Taparrabos & - & - & - & - & - & - & 1 & - & 1 \\
Bolsas & 4 & - & - & - & 2 & - & 40 & 4 & 46 \\
Fajas & - & - & - & - & - & - & 1 & - & 1 \\
Bolas de hilos & - & - & - & - & - & - & 1 & - & 1 \\
Hondas & - & - & - & - & - & - & 2 & - & 2 \\
Tejidos n/i & 8 & - & - & - & 1 & - & 4 & - & 13 \\
\hline TOTAL & 39 & - & 1 & - & 7 & - & 97 & 24 & 144 \\
\hline
\end{tabular}

Cuadro 1. Tejidos de los sitios de Yaye, Coyo-3, Quitor-9 y Solor-3 (según Le Paige y según nuestro registro del año 2000). 


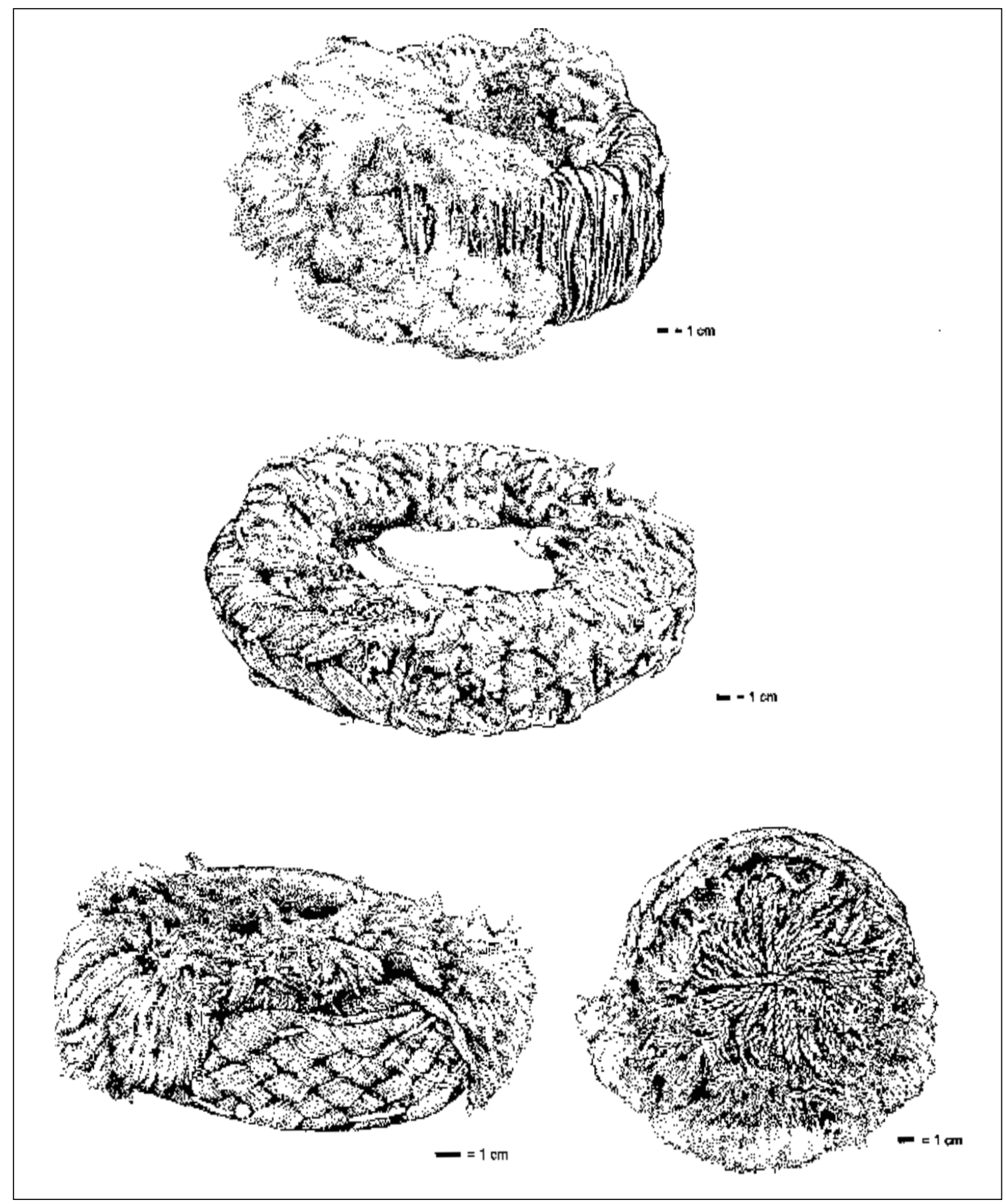

Figura 6. Gorros de piel o "tipo corona" de inicios del Período Intermedio Tardío, construidos con varios torzales en sucesión vertical, una trenza o un trenzado plano.

Finalmente, las bolsas parecen ser bastante uniformes, siendo las más numerosas aquellas pequeñas "bolsitas-amuletos" realizadas con restos de otros tejidos, seguidas de aquellas realizadas en sprang o torzal oblicuo doble. Llama la atención la escasa presencia de bolsas más "tradicionales" como talegas o wayuñas, ya que sabemos que la chuspa no suele presentarse en las ofrendas de entierros atacameños (Agüero et al. 1999). El resto de los textiles corresponde a pocos ejemplares de 
ovillos de lana, faja y honda, y a otros no identificados.

2.- Fase VII o Solor (1200-1470 DC). La tenemos representada en los sitios Solor-4, Solor-1, Solor2, Solor-5 (Le Paige 1964), Vilama (Le Paige 1963 Ms, 1964), Catarpe-2 (Le Paige 1961 Ms, 1962 Ms, 1964), Solcor Plaza (Le Paige Ms) y Pucara de Quitor, que tienden a integrar a los entierros -algunos de los cuales son en urnas- dentro o cerca de las estructuras habitacionales, como es el caso de Solor, Solcor y Catarpe. Nuevamente nos encontramos con que el emplazamiento en lugares cercanos al drenaje del río Vilama (Solor-4 y Solor-5), la destrucción por la instalación de una azufrera (Vilama) y el saqueo han afectado negativamente la conservación no sólo de los textiles sino de los contextos en general. No obstante, el emplazamiento de Catarpe-2 logró que se salvaran los obstáculos anteriores y contáramos con algunos escasos materiales para representar esta fase.

$\underline{\text { Solor-4. Varios son los sitios que incumben a esta }}$ fase en el extenso sector de los "campos de Solor" (Le Paige 1964). Efectivamente, Le Paige destaca que los montículos de Solor-4 deben ser estudiados junto a los de Solor-2 y Solor-1, que en un principio consideró por separado, pues están alejados y separados por el sitio Solor-3.

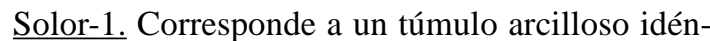
tico y contemporáneo al grupo de Solor-4, con jarros y urnas, al igual que el Túmulo oriental de Solor-2, donde Le Paige observó alfarería Rojo Violácea e incluso Inca, pero lamentablemente, producto del saqueo no quedó ningún entierro. También aquí se integra un túmulo con urnas idéntico a los de Solor-4, en la parte norte de Solor-3 (diferente al que tratamos en el acápite referente a la Fase Yaye). A todos ellos, Le Paige los considera como parte de los túmulos de Solor-4 formados por el derrumbe de viviendas de adobe donde se registraron dos tipos de entierros: unos más profundos en pozos, más bajos que los cimientos (pero relacionado con ellos); y otros en urnas afuera y dentro de las estructuras. Sin embargo, a veces las urnas de más de $1 \mathrm{~m}$ de altura no son funerarias, sino depósitos para el agua enterradas en el piso de la casa en cuyo caso están recubiertas de una capa gruesa de estuco blanco. Por otra parte, las sepulturas no están sólo en las esquinas sino también dentro o bajo los cimien- tos. Contabilizó un total de 31 entierros, entre los cuales los de niños eran en urnas, sin ajuar, y los de adultos eran "entierros ordinarios" con ajuar generalmente formado por un plato y un cántaro Rojo Violáceo y, en ocasiones, miniaturas. Instrumentos de hueso para la tejeduría, grandes palos de madera y manos de moler también componían estos ajuares -al igual que los de Yaye- descritos como "bastante pobres". Nada dice sobre los tejidos y si hubieran existido, no los encontramos en los depósitos.

Solor-5. Otro sector de Solor, relacionado al ámbito funerario, es Solor-5. Allí hay únicamente entierros en urnas dispuestas en hileras, sin restos de construcciones. El ajuar es inexistente dentro de las urnas, siendo el material depositado en superficie idéntico al de Solor-4 (Le Paige 1964).

Vilama. Asociados a la ocupación del Pucara de Vilama, Le Paige (1963 Ms y 1964) ubicó dos cementerios que habrían coexistido y que fueron arrasados por una planta azufrera: uno al borde del río con alfarería Rojo Violácea y otro en la terraza oeste del río (justo en la planta), con cerámica inca. Según Le Paige (1964), el ajuar del total de 14 entierros encontrados corresponde a la tercera fase del Agroalfarero atacameño, y entre sus componentes se cuentan los entierros en urnas y la desaparición de los gorros de piel (altos y delgados con parte superior de tejido grueso) que persisten en las demás sepulturas sin urna.

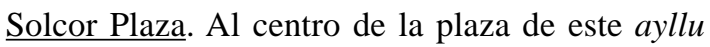
Le Paige (Ms) recuperó varios entierros marcados por palos, entre cuyos contextos describe una serie de textiles que no se conservaron:

a) 13 gorros de piel casi todos destruidos, "con fondo dibujado", de corona realizada "con un torzal", "vestigios de corona de paja de cuatro hebras", uno con "piel teñida a cuadros azules y rojos", "de piel teñido de rojo con el centro tejido en malla gruesa gris con dibujos", "con corona alta".

b) dos turbantes de tela "con dibujos negro y beige", "café oscuro".

c) tres túnicas "con bordes dibujados en colores".

d) seis bolsas entre las que se cuentan las "bolsitas-amuletos", bolsas "filet", una "bolsita" (¿?), y en un caso el contenido son "palitos". 
e) una manta "con dibujos".

f) una faja trenzada.

g) un tejido $\mathrm{n} / \mathrm{i}$.

Catarpe 2. En la localidad de Catarpe, al este de la quebrada del río San Pedro, se emplazan las ruinas del Tambo Inca, y al norte de él, el cementerio Catarpe-2 al que Le Paige (1962 Ms) llama "pueblo en forma de campamento". Dice haber encontrado allí una cueva al lado de una gran piedra plana con varias tumbas con cuerpos en cuclillas dentro de pozos tapados por grandes piedras planas de liparita, otras con tablas de madera muy toscas, varias sin nada indicadas por palos, y también algunos en urnas. En total recuperó 329 individuos cuyo ajuar no posee la cerámica roja de Catarpe-1 (ver más adelante), teniendo casi todas las tumbas "un plato de greda común, de variables dimensiones, vasos rústicos y mal moldeados, cestos planos, cajitas de madera cilíndricas y rectangulares, cucharitas, espátulas. Varias tabletas de rapé muy sencillas, con sus tubos. Abundantes calabazas pirograbadas" (Le Paige 1961 Ms, 1962 Ms, 1964). Afirma que este sitio es similar a Catarpe-3 y Catarpe-4, pero éstos no conservaban sus tejidos. Afortunadamente, Catarpe-2 cuenta con una fecha de $1185 \pm 70$ DC obtenida de una escudilla Dupont de la tumba 1855 (Berenguer et al. 1986), y se han conservado momias con sus tejidos, en los que Le Paige se detuvo con mayor detalle en su descripción, y algunos de los cuales pudimos, afortunadamente, registrar (Cuadro 2):

a) gran atención pone en los gorros de piel que llegan a sumar 59. Los hay de guanaco y de vicuña, entre los que se cuentan algunos teñidos de rojo; con la estructura de totora trenzada; otros con "algunos pedazos de la corona de piel, alto delgado" o con doble corona de paja; otros con la corona de paja de poca altura; también "quedan coronas hechas de tres y cinco corridas del mismo cordel de paja, una conserva [...] dos plumas de suri", otro plumas de parina; describe gorros sin y con casquete de "mailles trés espaciés" o bien "espaciés" octagonales, o simplemente gruesas y poco distanciadas o apretadas de "lana gruesa negra, borde blanco con plumero de cordeles cada uno con una pluma de parina"; mallas gruesas de dos colores; un "gorro lindo sobre la cabeza, alto [...] con plumero de cordeles cada una con su plumita de parina"; "quedan amarradas espinas de cactus en plumero"; con "centro lindo tejido dibujado en triángulos de colores". De estos 59 gorros se encontraron dos, más uno que Le Paige no había anotado, todos los cuales poseen la estructura de totora trenzada en forma plana forrada en un trozo de piel y con la malla del casquete anillada de color beige o anudada de tejido bastante grueso.

b) cinco gorros afelpados con "dibujos en azul, rojo y blanco, en forma muy baja con hoyo central; "lindo sombrerito de terciopelo de colores"; "gorro de terciopelo negro con colita"; "gorro de terciopelo y centro tejido apretado"; "gorro de terciopelo de varios colores, con orejas (cf. Solor3 momia 21)". Este último publicado por Llagostera y Costa (1984: 66) y por MChAP (1984: 67), gracias a lo cual es posible saber que efectivamente es similar al gorro de Solor-3 publicado por Berenguer (1993: 30), pero, a diferencia de él, el de Catarpe tiene la parte superior de las orejas listadas y una banda decorada con rombos escalonados en toda su circunferencia.

c) seis bonetes "de tejido bastante grueso de varias líneas paralelas de colores (carmín, blanco, azulito)"; "bonete tejido"; "bonet" tejido celeste, leche, café; "bonet" de tejido fino con dos plumas de parina; dos "bonet" de terciopelo café oscuro, uno con plumas de suri. En la exhibición del Museo de San Pedro existe un bonete hemisférico afelpado (tumba 1828) decorado con módulos pequeños con ganchos y escalerados en colores azul, rojo, amarillo y café rojizo. El afelpado se produce por la sujeción de hilados en todas las hileras de una estructura en anillado sencillo café oscuro (Figura 7).

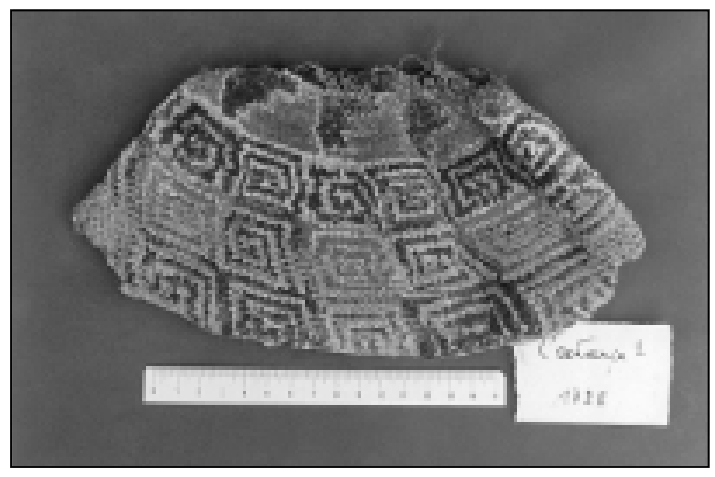

Figura 7. Bonete hemisférico afelpado (tumba 1828 de Catarpe-2) decorado con módulos pequeños con ganchos y escalerados. 
d) 29 túnicas. Cuando se trata de la túnica exterior Le Paige se refiere a ella como "poncho": "sobre todo, un poncho más oscuro", "tapada con grueso poncho café oscuro casi negro". Cuando es la túnica interior la llama "camiseta", y si es intermedia habla de "cotón": "cotón beige con borde "lie de vin" oscuro y unido por un bordado más delgado dibujado", "cotón con borde "lie de vin" oscuro", "cotón con borde concho vino y dibujos de lana".

Afortunadamente registramos 11 túnicas, cinco de las cuales no estaban consignadas en las notas del padre. De éstas, una es asignable al Tipo 3 también descrito para Solor-3 (ver Figura 4)- y presenta una lista a cada lado, de color café oscuro, con las uniones cosidas con un encandelillado. Las aberturas no llevan terminaciones. Tres pertenecen al Tipo 6A descrito para Qui-01 llamado Cementerio Oriente de Quillagua (Agüero 1998). En las uniones laterales y aberturas para brazos llevan una franja de 1 a $1.5 \mathrm{~cm}$ bordada en puntada satín en colores blanco, azul, rojo y café rojizo logrando motivos de cruces o volutas. Exhiben una lista café rojiza o roja de $3.5 \mathrm{~cm}$ de ancho adyacente al espacio bordado. Una es asignable al Tipo 6B, también reconocido en Qui-01 (Agüero 1998), y no lleva listas sino sólo un bordado en puntada satín con motivo de cruces o zigzag escalonado en blanco, azul y rojo, el cual cubre las uniones laterales. El vértice del cuello también está reforzado en puntada satín en rojo, azul y amarillo. Sin embargo, el grupo más numeroso lo constituyen cinco túnicas cuadradas o rectangulares monocromas de tonos café con las uniones laterales cosidas en festón simple o encandelilladas (Figura 8). Finalmente tenemos una túnica con dos listas juntas adyacentes a cada orilla de trama, una azul y otra café rojizo, y las uniones laterales encandelilladas, por ahora no asignable a tipo.

e) 53 bolsas de lana, entre las que se cuentan "saquitos-amuletos" o "bolsas fetiches", "uno con comida, chiquitito con líneas de colores", algunos de los cuales están alrededor del cuello; otros contienen maíz, semillas de algarrobo o "media calabaza periforme"; "un pedazo de tejido rojo de bolsa, con algarrobo"; otra "destruida de colores amarrada con cordel negro-blanco (contiene tres trozos de astiles y un tubito de madera); bolsas "filet" azul y rojo como las de Solor-3 (ver Figura 5B); otras bolsas decoradas como una "bolsa linda con dibujos [ganchos] en azul, rojo, café

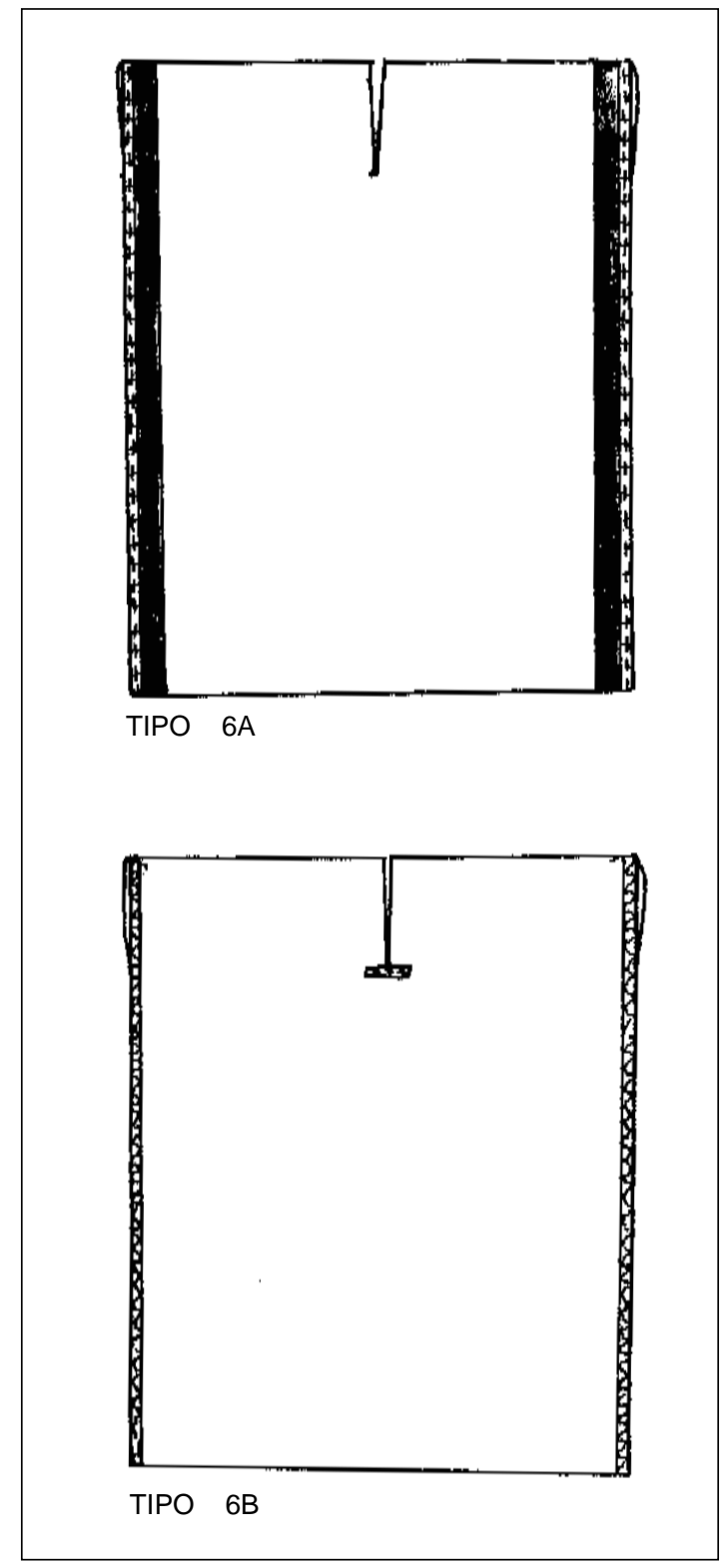

Figura 8. Tipos de túnicas de Catarpe-2 (tomado de Agüero 1998).

amarillento, adentro otra bolsa dibujada. Todo amarrado con un cordel. [...] otra bolsa plana hecha con tres líneas paralelas dibujada con café, café rosáceo y beige. Adentro tierra"; "una sobre el brazo derecho, chica, gruesa, dibujada (contiene una bolsa de cuero cerrada, una espátula-cucharita de madera, un tubito de hueso y un pedazo de espátula de hueso)"; "cuatro bolsas finas con semillas de algarrobo y comida"; "bolsa de tejido grueso rojo, café oscuro y amarillo con tableta para rapé sencilla, tubo de hueso con extre- 
midad de madera; y un saco largo angosto de varios colores (café y leche)".

En el registro de bolsas se contabilizó un total de seis de estas prendas: cinco "bolsitas-amuletos" y una bolsa "tradicional". Las primeras miden entre 10 a $12 \mathrm{~cm}$ de largo x 7.5 a $10 \mathrm{~cm}$ de ancho, confeccionadas con restos de otros tejidos en faz de urdimbre en los que se pudo detectar el uso de tramas múltiples y cuatro están unidas entre sí formando pares. En los cuatro casos en que se pudo ver, contenían granos de maíz. Por su parte, la segunda, de $15 \mathrm{~cm}$ de largo x $13 \mathrm{~cm}$ de ancho, está tejida en faz de urdimbre y presenta una lista central ancha siendo el resto de la superficie de color café ocre. Las uniones están cosidas con encandelillado y festón simple.

f) tres huinchas ("vincha").

g) dos ovillos de lana: "una pelota de hilo grueso"; "bolita de hilo en la boca".

h) una honda.

i) 38 tejidos n/i: "vestigios de tejidos bolsa o gorro"; "muchos pedazos de tejidos, algunos bordados"; "[momia] con todos los tejidos"; "casi todos los tejidos destruidos"; "muchos tejidos"; "varios pedazos de tejidos"; "tejidos quemados"; "paquete de tejidos envolviendo un canasto".

Como es posible observar en el Cuadro 2, la muestra que pudimos registrar en los sitios asignados a la Fase Solor es aun menor que aquella obtenida para Yaye, habiéndose encontrado sólo un 9.7\% de los textiles anotados por Le Paige. Sus observaciones indicarían que las prendas características de esta fase siguen el mismo orden que en la anterior, es decir, en primer lugar los gorros de piel $(32 \%)$, luego las bolsas $(26.2 \%)$ y las túnicas (14.2\%). Siguen los tejidos n/i y el resto de las prendas -a excepción de los taparrabos que están ausentes-, todos los cuales tienen una bajísima representación.

Según los datos, los gorros de piel siguen siendo frecuentes en los cementerios del Intermedio Tardío de San Pedro, todos los cuales mantienen algunas características de la etapa anterior, como la estructura de paja en forma de corona que puede estar construida con uno a cinco torzales en sucesión vertical, trenzada en forma plana y forrada en un trozo de piel de guanaco o vicuña natural, o teñida de rojo y con la malla del casquete anillada de color beige o anudada, de tejido bastante grueso. En Solcor Plaza, la mayoría de los gorros descritos tienen casquete, y en Catarpe hay con y sin, decorados y sin decorar. En ocasiones, cuando existe el casquete, hay un penacho de plumas de suri o de parina. Probablemente el gorro de Solcor Plaza con la piel teñida a cuadros rojos y azules haya estado construido con torzales de paja, los cuales pudieron haber sido envueltos en tiras de cuero teñidas de esos colores.

Al igual que en la etapa Yaye, están presentes los gorros afelpados y los bonetes. No obstante, esta

\begin{tabular}{|l|c|c|c|c|c|}
\hline SITIO & \multicolumn{2}{|c|}{ SOLCOR PLAZA } & \multicolumn{2}{c|}{ CATARPE- } & \multirow{2}{*}{ Total Le Paige } \\
\cline { 1 - 4 } PRENDA/ REGISTRO & Le Paige & $\mathbf{2 0 0 0}$ & Le Paige & $\mathbf{2 0 0 0}$ & \\
\hline Gorros piel & 13 & - & 59 & 3 & 72 \\
Gorros afelpados & - & - & 5 & - & 5 \\
Bonetes & - & - & 6 & 1 & 6 \\
Turbantes de tela & 2 & - & - & - & 2 \\
Túnicas & 3 & - & 29 & 11 & 32 \\
Mantas & 1 & - & - & - & -1 \\
Taparrabos & - & - & - & - & 59 \\
Bolsas & 6 & - & 53 & 6 & 3 \\
Fajas & 1 & - & 2 & - & 5 \\
Bolas de hilos & - & - & 5 & - & 1 \\
Hondas & - & - & 1 & - & 39 \\
Tejidos n/i & 1 & - & 38 & - & 225 \\
\hline TOTAL & 27 & - & 198 & 21 & \\
\hline
\end{tabular}

Cuadro 2. Tejidos de los sitios Solcor Plaza y Catarpe-2, según Le Paige y según nuestro registro del año 2000. 
vez hay una leve mayor representación de ambos, teniendo los primeros un $2.16 \%$ y los bonetes un 2.6\%. Cabe destacar que en Solcor Plaza no están presentes, en cambio, se registran por primera vez dos turbantes de tela $(0.86 \%)$ en Solcor Plaza. Entre los gorros afelpados de Catarpe-2 hay uno con orejas similar al de Solor-3 pero ahora tiene decoración polícroma. Por otra parte, la descripción que hace Le Paige de ciertos gorros afelpados bajos, decorados o de color oscuro, así como la reproducción que hacen Llagostera y Costa (1984: 66) en la que se observa el motivo de rombos escalonados en el gorro con orejas de Catarpe-2, nos permite compararlos con aquellos de Chacance-1 en el Loa Medio (MChAP 1993), similares a uno que pertenece a la Colección Echeverría y Reyes (Iriarte y Renard 1998: 85) y que parece provenir de esta zona.

Por otra parte, respecto al bonete, aquí tenemos la seguridad de que hay ejemplares tejidos en anillado sencillo, y otros en los que la sujeción de hilados en cada hilera de una estructura en esa técnica crearía el efecto de "terciopelo" o afelpado, en cuyo caso un ejemplar muestra motivos de ganchos y escalonados de colores artificiales, y otro dibujado por Le Paige exhibiría listas horizontales. Según los dibujos realizados por el padre, además de forma hemisférica tendría forma de cono. Hasta el momento no tenemos noticias de que este tipo de gorros haya sido detectado en otras localidades de Atacama.

Los turbantes de tela de Solcor Plaza constituyen una excepción y su escaso número (sólo dos) no nos permite hablar de ellos como una prenda característica del sitio, y menos de la fase.

También hubo ciertas coincidencias entre las apreciaciones de las túnicas que hiciera Le Paige y nuestro registro. Efectivamente, él consignó la presencia de túnicas con una lista lateral concho de vino y con "dibujos de lana" en las uniones. En las escasas prendas analizadas se pudo detectar la presencia del Tipo 3, del Tipo 6A, del Tipo 6B (Agüero 1998) y cinco túnicas café monocromas, las que no habían sido informadas hasta este momento. Los dos primeros pueden coincidir con las descripciones de Le Paige, pudiendo ser el color "concho de vino", que él advierte, un tono café rojizo que bien podría estar decolorado. El Tipo 3 descrito para Solor-3, y característico de los si- tios asignados a la Fase Yaye, ahora presenta listas café oscuras en vez de rojas, pero sigue utilizando tramas múltiples. Resulta de interés que el Tipo 6A constituya el tipo de túnica mejor representado en Quillagua.01-02 (Cementerio Oriente de Quillagua: 980-1100 DC) ${ }^{2}$ con un $18 \%$. Allí también se identificó el Tipo 6B con un $1.3 \%$ de representación, los que en ese entonces fueron asignados al estilo atacameño presente en el Loa Inferior a partir de la presencia de ciertos atributos tales como la forma, la técnica de bordado y, fundamentalmente, la utilización de tramas múltiples (Agüero 1998). Todas las túnicas que pudimos observar en Catarpe-2 presentan este particular atributo.

Por último, entre las bolsas parece haber la misma variedad que en Yaye, vale decir, las pequeñas "bolsitas-amuletos" realizadas con restos de otros tejidos en los que se pudo apreciar el uso de tramas múltiples, y las bolsas realizadas en sprang o torzal oblicuo doble ("filet", sensu Le Paige). Pero ahora, además, pudimos registrar bolsas "tradicionales" que, al parecer, estaban ausentes en los contextos de la fase anterior. El resto de los textiles corresponde a pocos ejemplares de ovillos de lana, faja y honda, y a otros no identificados.

4.- Fase VIII o Catarpe Inca. El sitio más conocido de este momento es el Tambo de Catarpe, al que se asocia el cementerio Catarpe-1 (Le Paige 1961 Ms, 1962 Ms y 1964 Ms), aunque también están Solor Ayllu (Le Paige Ms), Hostería San Pedro, Peine (Mostny 1948) y los santuarios de altura ubicados en el volcán Pili (Dransart 1995), Licancabur y Quimal (Revista del C.I.A.D.A.M. 1978). Los contextos muestran aríbalos y cántaros Inca Local, Inca Paya y Rojo Violáceo, placas de bronces santamarianas y miniaturas incaicas vinculando a los oasis principalmente con el Noroeste argentino. La muestra de textiles en estos sitios es prácticamente inexistente, conservándose algunos de Peine y del volcán Pili.

Solor Ayllu. Le Paige (Ms) registró en entierros en urnas con asociación a alfarería Inca e Inca Local (Tarragó 1989) tres túnicas, una bolsa con espinas de cactus, otra con cráneo de feto, una bolsa gruesa y dos "pelotas de lana".

\footnotetext{
2 Agüero y colaboradores (1998).
} 
Peine. Aun cuando no se mencionan textiles para este sitio, el trabajo en los depósitos del Museo de San Pedro nos permitió encontrar fortuitamente un gorro de piel "tipo corona", de estructura alta de paja trenzada en forma plana (ver Figura 6), y una bolsa rectangular, bastante reparada, de $20 \mathrm{~cm}$ de largo x $24 \mathrm{~cm}$ de ancho, tejida en faz de urdimbre con hilados monocromos y regulares 2Z-S tanto en la trama como en la urdimbre, y completamente decorada con la técnica de urdimbres transpuestas con motivos de listas lisas y bifurcadas y rombos en colores beige, amarillo, azul y rojo. Las uniones laterales están cosidas con un festón simple y las orillas de urdimbre terminadas en un festón anillado doble en tramos de colores alternados azul y beige (Figuras 9 y 10).

Cerro Pili. Por otra parte, en los santuarios de altura tales como el cerro Pili, el Quimal y el volcán Licancabur se encontraron figuritas de concha y de plata masculinas y femeninas vestidas

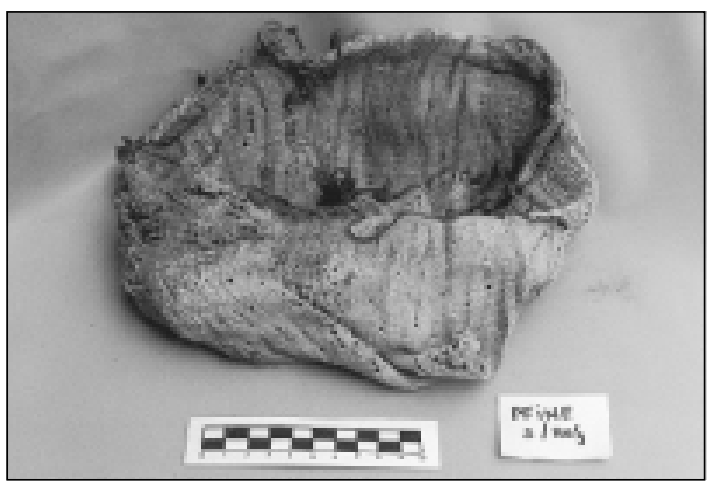

Figura 9. Bolsa decorada en técnica de urdimbres transpuestas, proveniente de Peine.

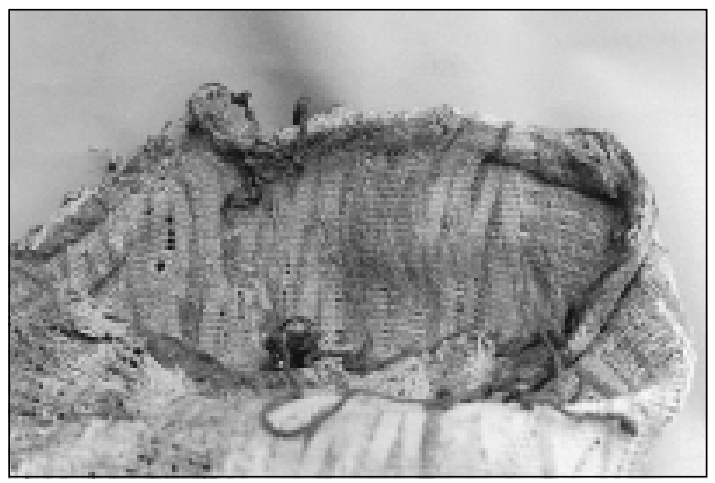

Figura 10. Detalle de decoración en técnica de urdimbres transpuestas de bolsa proveniente de Peine. con indumentaria incaica miniatura que ha sido analizada, descrita y publicada por Dransart (1995). En el caso de las vestimentas de las figuritas del cerro Pili, algunas de las cuales están en exhibición en el Museo R. P. Gustavo Le Paige en San Pedro de Atacama, Dransart (1995) analiza de la vestimenta femenina:

a) un aqsu tejido en faz de urdimbre y decorado con urdimbres complementarias que crean bandas con motivos incaicos característicos tales como zigzags y "ojos" en rojo y amarillo intercaladas por listas lisas blancas, rojas, verdes y moradas. Las orillas están terminadas en festón anillado cruzado.

b) una faja tejida en faz de urdimbre doble tela con un cordón trenzado. Los motivos son zigzags y "ojos" realizados en rojo, amarillo y verde pálido. Las orillas de urdimbre están terminadas en un festón anillado cruzado rojo y amarillo.

c) un tocado confeccionado en anillado sencillo en fibra vegetal café con aplicación de plumas naranjas y en la parte inferior, amarillas. Este tocado forma un conjunto con una coleta tejida en faz de urdimbre con hilados de fibra de camélido con aplicación de plumas naranjas en su superficie, y de una flecadura azul piedra en su extremo inferior.

Y la masculina:

a) una manta tejida en faz de urdimbre color café monocroma con orillas terminadas en festón simple y festón anillado cruzado morado y rojo.

b) una túnica rectangular tejida en faz de urdimbre color café con la parte inferior con un zig-zag rojo, amarillo y verde bordado simplemente en puntada zigzag. Las aberturas para los brazos y la inferior van terminadas en un festón anillado cruzado, en tanto las uniones laterales están cosidas en puntada en ' 8 '. El color de estas terminaciones es rojo, amarillo, negro, verde y café oscuro. La abertura del cuello está terminada en festón simple beige.

c) una bolsa tejida en faz de urdimbre con listas lisas y en damero en tonos naturales y tirante tejido en doble tela. Las uniones laterales están cosidas en festón anillado cruzado en rojo y amarillo y la abertura está terminada en festón simple rojo. 


\begin{tabular}{|c|c|c|c|c|c|c|}
\hline \multirow{2}{*}{$\begin{array}{l}\text { SITIO } \\
\text { PRENDA/ REGISTRO }\end{array}$} & \multirow{2}{*}{$\begin{array}{c}\text { PEINE } \\
2000\end{array}$} & \multicolumn{2}{|c|}{ SOLOR AYLLU } & \multicolumn{2}{|c|}{$\mathrm{C}^{\mathbf{0}}$ PILI } & \multirow{2}{*}{ Total } \\
\hline & & Le Paige & 2000 & Dransart & 2000 & \\
\hline Gorros piel & 1 & - & - & - & - & 1 \\
\hline Gorros afelpados & - & - & - & - & - & - \\
\hline Bonetes & - & - & - & - & - & - \\
\hline Turbantes de tela & - & - & - & - & - & - \\
\hline Tocado de plumas & - & - & - & $1^{*}$ & $1^{*}$ & 1 \\
\hline Túnicas & - & 3 & - & $1^{*}$ & $1^{*}$ & 4 \\
\hline Mantas & - & - & - & $1^{*}$ & $1^{*}$ & 1 \\
\hline Taparrabos & - & - & - & - & - & - \\
\hline Bolsas & 1 & 4 & - & $1^{*}$ & $1^{*}$ & 6 \\
\hline Fajas & - & - & - & $1^{*}$ & $1^{*}$ & 1 \\
\hline Bolas de hilos & - & 2 & - & - & - & 2 \\
\hline Hondas & - & - & - & - & - & - \\
\hline Tejidos n/i & - & - & - & - & - & - \\
\hline Aqsu & - & - & - & $1^{*}$ & $1^{*}$ & 1 \\
\hline TOTAL & 2 & 9 & 0 & $6^{*}$ & $6^{*}$ & 17 \\
\hline
\end{tabular}

Cuadro 3. Tejidos de los sitios Peine, Solor Ayllu y Cerro Pili (*Asterisco indica prendas miniatura).

Todos estos atuendos están elaborados en técnicas faz de urdimbre, doble tela y urdimbres complementarias, y en anillado sencillo en hilados 2Z-S de fibra de camélido, salvo parte del tocado femenino. Las terminaciones utilizadas son el festón simple, el festón anillado sencillo y la puntada en ' 8 ' en tramos de colores blanco, azul, rojo, amarillo, verde, morado. Los motivos más vistos son el zigzag y los "ojos".

El Cuadro 3 muestra los poquísimos tejidos que pudimos rastrear en bibliografía, exhibición y depósito $(n=16)$. La mayoría de ellos no fue encontrado $(n=9)$, otros corresponden a miniaturas incaicas $(n=6)$, y sólo uno de ellos podría tratarse de un textil tardío local, proveniente de Peine.

Aunque el tamaño de la muestra de la Fase Catarpe Inca no nos permite afirmar nada con certeza, sí podemos distinguir un nuevo conjunto textil, el incaico, que presenta nuevas combinaciones de técnicas y colores, aun cuando está reservado a un contexto sumamente específico, diferente al del resto de los textiles considerados. Hay que señalar que el estudio de los textiles inca se ha focalizado en prendas elitistas (Dransart 1995, Mostny 1957, Michieli 1990, Rowe 1978 y 1995-1996), lo que impide tener información acerca de su comportamiento en otros contextos con los que eventualmente po- drían ser comparadas las prendas locales de los oasis de San Pedro. ${ }^{3}$

Aparte de las miniaturas incaicas, la descripción de Le Paige de los textiles de Solor Ayllu y la inexistencia de prendas en Catarpe-1 y Hostería no nos ayuda a saber más de la textilería san pedrina. Sin embargo, la penosa situación anterior se ve en parte recompensada por el hallazgo casual de un gorro de piel de Peine, que hace el vínculo con las fases anteriores, y de una bolsa del mismo sitio que nos aporta una interesante información. El estilo de la bolsa (técnica de urdimbres transpuestas, colores y decoración) la inserta en el componente que ha sido asignado a la Fase Turi de la cuenca del Loa (Agüero et al. 1997 y 1999) hacia los finales del Período Intermedio Tardío.

En síntesis, la revisión exhaustiva de las notas de Le Paige, y el trabajo con colecciones del Museo Arqueológico que creara, nos ha permitido reunir información (Cuadro 4) a partir de la cual elaborar una secuencia preliminar de la textilería en los oasis del Salar de Atacama durante los Períodos Intermedio Tardío y Tardío, que intentaremos integrar a la secuencia textil regional.

\footnotetext{
3 Este problema podría subsanarse con los estudios de Ulloa en Camarones y Azapa-115, que serán prontamente publicados.
} 


\begin{tabular}{|l|r|r|r|r|}
\hline PRENDA / FASE & YAYE & SOLOR & CATARPE & Total \\
\hline Gorros piel & 48 & 72 & - & 120 \\
Gorros afelpados & 2 & 5 & - & 7 \\
Bonetes & 2 & 6 & - & 8 \\
Turbantes de tela & - & 2 & - & 2 \\
Tocado de plumas & - & - & 1 & 1 \\
Túnicas & 28 & 32 & 4 & 64 \\
Mantas & - & 1 & 1 & 2 \\
Taparrabos & 1 & - & - & 1 \\
Bolsas & 46 & 59 & 6 & 5 \\
Fajas & 1 & 3 & 2 & 8 \\
Bolas de hilos & 2 & 5 & - & 3 \\
Hondas & 13 & 1 & - & 1 \\
Tejidos ni & - & - & 1 & 52 \\
Aqsu & 144 & 225 & 16 & 385 \\
\hline TOTAL & 14 & & \\
\hline
\end{tabular}

Cuadro 4. Tejidos recopilados de los sitios del Período Intermedio Tardío y Tardío del Salar de Atacama (*Asterisco indica prendas miniatura).

\section{La textilería del Salar de Atacama durante el Período Intermedio Tardío}

En los oasis de San Pedro, cuando la hegemonía de Tiwanaku empieza a debilitarse, una parte de la sociedad local pareciera redefinir sus patrones culturales simplificándolos a sus atributos más esenciales, mientras que la otra intentaría demostrar cierta continuidad con los momentos anteriores. Es así como durante los inicios del Período Intermedio Tardío, si bien algunos cementerios del Período Medio siguen siendo ocupados y los contextos varían, pero todavía continúan integrando artefactos visualmente muy atractivos manteniendo un cierto estilo de "abundancia", otros grupos se entierran en lugares emplazados lejos de los lugares de habitación y las ofrendas y ajuares no poseen el despliegue de colores e iconografía de aquellos del Período Medio, todo lo cual llevó a varios autores a referirse a los contextos como "empobrecidos". No obstante, diferimos de este apelativo puesto que la mayoría tiene ajuar y ofrendas, aunque diferentes (ref. notas de campo de Le Paige). Es evidente que en esta etapa la foraneidad disminuye notablemente y ya no está representada por Tiwanaku y Aguada, sino únicamente en Quitor9 por algunas vasijas del área de Potosí (Tarragó 1989: 452), de manera que se empieza a sentir en los oasis una relativa independencia de otros centros culturales.

La información general entregada para los sitios asignados a la Fase Yaye en los inicios del Pe- ríodo Intermedio Tardío nos permite identificar como una prenda conspicua de sus contextos a los gorros de piel "tipo corona", y como excepción a los gorros afelpados; luego a los "saquitos-amuletos", las bolsas tejidas en sprang o torzal oblicuo doble -ambas prendas ausentes en el período anterior- y túnicas que muestran una gran homogeneidad, distribuyéndose los 18 ejemplares analizados en sólo tres tipos (Agüero 1998). Es así como en esta primera etapa del Intermedio Tardío se aprecia una popularidad creciente de los gorros de piel "tipo corona", los que, si bien todavía presentan una gran variabilidad en su construcción, van dejando atrás las formas bajas construidas con uno o dos torzales en favor de las estructuras trenzadas planas o con varias corridas de torzales que crean estructuras más altas. Además el casquete se construye con técnica de anillado siguiendo la tradición local observada por Oakland (1992) durante el Período Medio en Coyo Oriente.

Hasta el momento dentro de los oasis de San Pedro hemos visto prendas que tienen antecedentes en el Período Medio local, como es el caso de los gorros de piel o "tipo corona", que ahora son más altos que aquellos descritos para ese período, y de las túnicas cuadradas o rectangulares. De hecho, el Tipo 3 (Agüero 1998) corresponde al Tipo 1 del Grupo A de Oakland (1992) y otros elementos que constituyen los Tipos 1 y 2 de Agüero (1998) también cuentan con antecedentes en los oasis, como, por ejemplo, en Coyo Oriente, 
Quitor-6 y Solcor-3, entre otros. En ellos son frecuentes los bordados laterales en puntada satín, así como también en la abertura para el cuello en forma de prolongaciones o apéndices. No obstante, también es notoria la ausencia de una serie de elementos que conforman el conjunto textil san pedrino característico del Período Medio (Oakland 1992, Uribe y Agüero 2000), tales como la decoración de túnicas por un conjunto de listas laterales lisas o decoradas por urdimbres flotantes y complementarias que ocupaban una buena porción de la superficie de túnicas, el uso de colores de tonalidades verdes, azules y amarillas y los gorros de piel con carrillera, ${ }^{4}$ que parecen ir desapareciendo a medida que nos adentramos en el período que nos ocupa, presentándose en Solor-3 únicamente en las túnicas, listas laterales poco notorias. Sin embargo, todos los tipos textiles que Oakland (1992) asigna a un estilo local (su Grupo A) y en especial su Tipo V -presente en Coyo Oriente, Solcor-3 y Quitor-1 y que la autora sitúa cronológicamente entre el 800-1000 DC por su asociación a alfarería Roja Violácea- comprenden varias listas laterales lisas y decoradas en urdimbres complementarias, y está bastante bien representado en otros sectores del territorio atacameño como los cursos medio e inferior del río Loa (Chiu Chiu, Quillagua) durante la primera mitad del Período Intermedio Tardío en contextos que se han asignado a la Fase Solor (en Quillagua-01-02; Agüero 1998, Agüero et al. 1997 y 1999). Estos contextos muestran una fuerte presencia de elementos tarapaqueños del oasis de Pica, al mismo tiempo que una continuidad en la ocupación que está registrada, por lo menos desde finales del Período Medio. También, por otro lado, y de manera sincrónica, algunos depósitos asignados a la Fase Yaye han sido informados para Quillagua03 (Cementerio Poniente), el que evidencia una fuerte ocupación por parte de poblaciones atacameñas (Agüero et al. 1997 y 1999), todo lo cual reproduce la situación observada en San Pedro de Atacama. Vale decir, por una parte existen cementerios con ocupaciones que se extienden en forma continua desde el Período Medio hasta la Fase Solor con un alto índice de foraneidad en

4 Este conjunto ha sido definido a partir de lo observado en Coyo Oriente, Quitor-2, Quitor-6 y Solcor-3, con fechas que van del 500 al 950 DC, (Berenguer et al. 1986), y se aparta de aquel conjunto textil Tiwanaku que es contemporáneo. las cuales todavía se advierten elementos característicos de momentos más tempranos (p.e. TIPO V de Oakland 1992, y contextos abundantes), y por otra, cementerios unicomponentes con una ocupación a partir del 900 DC que exhiben las características atribuidas a la Fase Yaye. Es en éstos $-\mathrm{y}$ no en aquellos que si bien tienen una ocupación en un momento contemporáneo a ella, sus contextos son asignables mayoritariamente al Período Medio- donde vemos una simplificación del estilo textil, o una reducción a sus atributos más definitorios (faz de urdimbre, uso de tramas múltiples, puntada satín), lo que es coincidente con lo observado en la cerámica, en que las vasijas monocromas y pulidas de la tradición San Pedro dan paso a las escudillas Dupont (Agüero et al. 1999).

De esta manera pareciera que la secuencia Coyo, Yaye, Solor muestra variabilidad, existiendo: a) ausencia de contextos Yaye en cementerios con ocupaciones que se extienden desde el Período Medio al Intermedio Tardío, b) un momento sincrónico entre Yaye y Solor tal como lo muestran los distintos cementerios san pedrinos, y c) dos versiones textiles de la Fase Solor, por un lado aquella que planteábamos en la introducción y que está representada en los cementerios de Coyo Oriente, Solcor-3 y Quillagua-01-02 asociados principalmente a alfarería Roja Violácea y Rojo Burdo -y cuyos elementos han sido descritos por Oakland (1992) en parte de su Grupo A, ${ }^{5}$ y por Agüero (1998) y Agüero y cols. (1997 y 1999) para la primera mitad del Período Intermedio Tardío; y por la otra, una versión que hemos identificado en los restos textiles de Catarpe-2, también asociada a alfarería Roja Violácea y Roja Burda. Es esta variante textil del estilo san pedrino la que es desarrollada al interior del oasis resultando clara la continuidad a partir de la textilería de la Fase Yaye, evidenciada tanto en el uso de los gorros de piel que ahora se hacen más predominantemente altos y delgados, en las bolsas en sprang o torzal oblicuo doble, en el uso de gorros afelpados y bonetes, en las túnicas con una discreta lista café o café rojiza (¿concho de vino desteñido?) a los lados y uniones tapadas en bordados angostos en puntada satín, agrupadas en los Tipos 3 (también presente en la Fase Yaye), 6A y

\footnotetext{
5 Aunque esta autora los asigna principalmente al Período Medio de San Pedro.
} 
6B, así como en la ausencia de túnicas con bloques de listas polícromas a los lados (Tipo V de Oakland). Sin embargo, en esta ocasión se pudo identificar que dos de los tipos de túnicas registrados (6A y 6B) en Catarpe-2 forman parte del grupo más numeroso en Quillagua-01-02, poniendo en evidencia la coexistencia de las dos versiones textiles Solor en un mismo espacio, precisamente las mismas que en San Pedro ocurren separadas.

Es decir, a partir de los estudios en Quillagua (Agüero et al. 1997 y 1999) vimos que fuera del oasis san pedrino hubo coexistencia espacial de dos versiones textiles de la etapa que ahora podemos llamar Yaye-Solor. Nos referiremos como "Solor, a la versión que se presenta en el oasis durante el Intermedio Tardío en sitios con ocupaciones previas del Período Medio y que también tiene una variante desarrollada en el Loa. En cambio a aquella versión que se registró principalmente en sitios ocupados a partir de los inicios del Período Intermedio Tardío o durante su primera mitad (como Yaye, Solor-3 y Catarpe-2), la denominaremos Yaye. De esta situación concluimos que las tradicionales fases Yaye y Solor forman parte de un solo momento transicional relacionado con el debilitamiento de la hegemonía de Tiwanaku y con la redefinición de los patrones culturales propios.

Aun cuando todo lo anterior pareciera indicar que este momento cultural necesita ser mejor delimitado cronológicamente, pudiendo las dos versiones textiles mencionadas variar en su extensión temporal, sin duda resulta claro que durante el momento Yaye-Solor, en la población atacameña existe una intención por definir y delimitar la extensión de su territorio, lo que hasta el momento, y desde la perspectiva de nuestros materiales, parece ocurrir en dirección a los cursos Medio e Inferior del río Loa.

Además, el trabajo realizado nos permite plantear que este comportamiento textil con el que hemos caracterizado la textilería Solor, al contrario de la Yaye, se asocia a situaciones de continuidad cultural de acuerdo a su permanencia en sitios en los que existe una ocupación previa correspondiente al Período Medio como Chiu Chiu (Agüero 2002 Ms-a).

Por lo tanto y en definitiva, podemos caracterizar a la textilería Yaye como la más representativa del
Período Intermedio Tardío de los oasis de San Pedro, mientras que la versión Solor constituye un remanente de los vínculos culturales establecidos durante el Período Medio.

Finalmente, respecto a la Fase Catarpe, resulta desalentador no haber podido contar con los textiles del cementerio Catarpe-1, por lo que no nos podemos pronunciar en relación a ella.

No obstante, en Peine contamos con un gorro tipo corona y una bolsa decorada en técnica de urdimbres transpuestas, la que resulta sumamente indicadora de una presencia puneña ${ }^{6}$ tardía identificada en textiles decorados por medio de la técnica de urdimbres transpuestas y tapicería enlazada dentada o "dovetailed". Se ha podido reconocer que tejidos de este tipo se encuentran distribuidos desde la desembocadura del río Loa por el oeste, sus cursos Inferior y Medio, hasta el noroeste de Argentina por el este, en contextos de finales del Intermedio Tardío (1395-1480 DC), que se extienden hasta la llegada de la presencia incaica (ver más arriba; también Agüero et al. 1997 y 1999).

Respecto a los gorros de piel, cabe destacar su ausencia en el Loa Inferior, mientras que ejemplares similares a los de Catarpe- 2 y Peine proceden del territorio vecino de Casabindo (Cementerio VI), uno de los cuales es publicado por Renard (1997) quien cita la descripción de LehmannNitsche (1904):

"consiste en una corona de paja [...] envuelta con largos pedazos de cuero de guanaco o vicuña. De una parte cuelga un cordón de lana negra. El espacio interno de la corona está rellenado con un tejido circular de lana, cuya estructura se ve en la figura indicada. En el centro hay entretejida una estrellita de lana negra, de la que cuelgan hilos sueltos; en las extremidades libres de éstos están atadas por medio de un tendón muy fino, una plumas de loro, verdes y coloradas, así que cada hilo tiene atada una pluma."

6 Pese a lo limitado de la muestra, no hemos advertido en los textiles examinados ninguno de los atributos característicos de la textilería de Puqui situado en el Altiplano Meridional (Agüero 2000), lo que, sin duda, requiere de más investigación, tanto en lo que se refiere a localizar materiales locales como a analizar la totalidad de aquellos que proceden de las cuevas de esa área de Bolivia. 
También este tipo de gorros es mencionado por Lindberg (1969) y Mostny (1952: 3) para Chiu Chiu y Lasana (Cementerio de Los Antiguos), anudados y con casquete de malla muy gruesa y confeccionados con tiras de piel. Por otra parte, el dibujo de un atacameño usando probablemente uno de estos gorros durante el siglo pasado (Bresson 1875) extiende considerablemente su uso en el tiempo y lo reafirma como un elemento identitario de esta cultura.

La identificación en Peine (al sur del Salar) de este componente tardío del estilo textil de la Subárea Circumpuneña nos lleva a proponer en forma preliminar que, probablemente, el momento que hemos asignado a la Fase Turi en la cuenca del Loa esté presente en la zona de quebradas altas del Salar de Atacama, y ausente en las zonas bajas cercanas a los ríos Vilama y San Pedro.

Aun así, el estilo textil de la Fase Turi se reafirma como un nuevo indicador cultural que se suma a la alfarería, aportando un marcador cronológico cuya distribución y asociaciones muestran una homogeneidad material que da cuenta de patrones culturales compartidos, afirmando una cierta unidad del territorio de Atacama durante este momento, en el cual se desarrollaría el mayor nexo con el Noroeste argentino, así como también su máxima extensión, cubriendo desde esa área por el este hasta la desembocadura del Loa por el oeste, tal como lo demuestra la presencia de un textil Turi asociado a un jarro inca local en Caleta Huelén 52 (Agüero 1997 Ms).

De este modo, la revisión de textiles realizada en San Pedro de Atacama y la comparación con muestras procedentes de otros espacios del territorio atacameño tales como el Loa Inferior, Medio y Noroeste de Argentina, corrobora la existencia de un estilo textil circumpuneño el que habíamos enunciado en trabajos anteriores, pero al que le faltaba representación en estos oasis. Ahora proponemos la presencia de este momento cultural en las quebradas altas del Salar de Atacama, ya que en las zonas bajas cercanas a los ríos Vilama y San Pedro no fue detectado. En efecto, la distribución espacial de estas prendas sugiere una situación "expansiva" de la población atacameña, que sin embargo y como decíamos, no está presente en el oasis mismo de San Pedro, sino que alrededor de éste, sugiriendo quizás, junto a la ausencia de fechas existentes para este momento en dicho oasis, un cambio en los patrones de asentamiento relacionados con la influencia de las poblaciones procedentes desde las tierras altas e identificadas por primera vez en el Loa Superior.

\section{REFERENCIAS CITADAS}

AGÜERO, C., 1998. Tradiciones textiles de Atacama y Tarapacá presentes en Quillagua durante el Período Intermedio Tardío. Boletín del Comité Nacional de Conservación Textil 3: 103-128, Santiago.

1999 Ms. Textiles e iconografía Tiwanaku: Patrones distribucionales en zonas de frontera. Enviado a Estudios Atacameños.

2000. Las tradiciones de Tierras Altas y de Valles Occidentales en la textilería arqueológica del valle de Azapa. Chungara vol. 32 (2): 217 - 225, Arica.

2002 Ms. El componente Tiwanaku en los oasis de San Pedro. Estudio de la textilería de tres sitios del Período Medio (Primera Parte). Informe $1^{\circ}$ Año Proyecto FONDECYT 1010735

2002 Ms-a. Textiles del Período Intermedio Tardío de San Pedro de Atacama y su relación con los de la cuenca del Loa. Informe $2^{\circ}$ Año Proyecto FONDECYT 1000148
AGÜERO, C. y J. CORREA, 1997 Ms. Cercanía y distancia entre Atacama y Tarapacá en el Loa Inferior durante el PIT. Informe $2^{\circ}$ Año Proyecto FONDECYT 1950071

AGÜERO, C., M. URIBE, P. AYALA y B. CASES, 1997. Variabilidad textil durante el Período Intermedio Tardío en el valle de Quillagua: Una aproximación a la etnicidad. Estudios Atacameños 14: 263-290, San Pedro de Atacama.

— 1999. Una aproximación arqueológica a la etnicidad: El rol de los textiles en la construcción de la identidad cultural en los cementerios de Quillagua (norte de Chile). Gaceta Arqueológica Andina 25: 167-198, Lima.

ALDUNATE, C., 1993. Arqueología del Pukara de Turi. Actas del XII Congreso Nacional de Arqueología Chilena, Temuco 1991, Boletín del Museo Regional de la Araucanía Tomo II, 4: 61-78, Temuco. 
BENAVENTE, A., 1982. Chiu Chiu 200: Una comunidad pastora temprana en la provincia del Loa (II Región). Actas del IX Congreso Nacional de Arqueología Chile$n a$, pp. 75-94, La Serena.

BERENGUER, J., 1993. Gorros, identidad e interacción en el desierto chileno antes y después del colapso de Tiwanaku. En: Identidad y prestigio en los Andes: Gorros, turbantes y diademas. Catálogo de Exposición, pp.: 41-64. Museo Chileno de Arte Precolombino, Santiago.

BERENGUER, J., A. DEZA, A. ROMAN y A. LLAGOSTERA, 1986. La secuencia de Miriam Tarragó para San Pedro de Atacama: Un test por termoluminiscencia. Revista Chilena de Antropología 5: 17-54, Santiago.

BRESSON, A., 1875. Le désert d'Atacama et Caracoles (Amérique du Sud), par l' Ingénieur A. Bresson, 18701874. Texte et dessins inédits. En Le tour du Monde. Nouveau Journal des Voyages, t. XXIX, fascículos 750751, pp. 321-352.

BOMAN, E., 1908. Antiquités de la région andine de la République Argentine et du desert d'Atacama. Paris: Imprimerie Nationale.

COSTA, M. A. y A. LLAGOSTERA, 1994. Coyo 3: Momentos finales del Período Medio en San Pedro de Atacama. Estudios Atacameños 11: 73-108, San Pedro de Atacama.

DRANSART, P., 1995. Elemental meanings: Symbolic expression in Inka miniature figurines. Research Papers 40, Institute of Latin American Studies, University of London.

EMERY, I., 1981. The primary structures of fabrics. The Textile Museum, Washington D.C.

FRAME, M., 1986. Nasca sprang tassels: Structure, technique and order. The Textile Museum Journal 25, Washington D.C.

IRIARTE, I. y S. RENARD, 1998. Textiles del norte de Chile en la Colección Echeverría y Reyes del Museo Etnográfico de la Universidad de Buenos Aires. Boletín del Comité Nacional de Conservación Textil 3: 81-101, Santiago.

LATCHAM, R. 1938. La arqueología de la región atacameña. Prensas de la Universidad de Chile, Santiago.

LE PAIGE, G., 1957 / 58 / 59. Antiguas culturas atacameñas en la cordillera chilena. Anales de la Universidad Católica de Valparaíso 4-5, Santiago.

- 1964. El precerámico en la cordillera atacameña y los cementerios del Período Agroalfarero de San Pedro de Atacama. Anales de la Universidad del Norte 3, Antofagasta.

- 1958-1961-1962-1963- 1964-1968-1977 Ms. Notas de campo de Yaye, Quitor, Solcor, Solor, Vilama y Catarpe. Biblioteca Museo R.P. Gustavo Le Paige s. j., San Pedro de Atacama.

LINDBERG, I., 1960. Un nuevo tipo de sombrero atacameño. Universidad de Chile, Santiago.
LLAGOSTERA, A. y M. A. COSTA, 1984. Museo Arqueológico R.P. Gustavo Le Paige s.j. Serie Patrimonio Cultural Chileno. Colección Museos Chilenos. Universidad del Norte, San Pedro de Atacama.

MICHIELI, C. T., 1990. Textilería incaica en la provincia de San Juan: Los ajuares de los cerros Mercedario, Toro y Tambillos. Instituto de Investigaciones y Museo, Universidad Nacional de San Juan, San Juan.

- 1994. Textilería de la Cultura Calingasta. Publicaciones 21: 9-35, San Juan.

MOSTNY, G., 1948. Ciudades atacameñas. Boletín del Museo Nacional de Historia Natural XXIV: 125-212, Santiago.

- 1956. Una tumba de Chiu Chiu. Boletín del Museo Nacional de Historia Natural, XXVI: 1-55, Santiago.

— 1957. La momia del cerro El Plomo. Boletín del Museo Nacional de Historia Natural, vol. XXVII (1): 31-74, Santiago.

MUSEO CHILENO DE ARTE PRECOLOMBINO, 1988. Tesoros de San Pedro de Atacama. Museo Chileno de Arte Precolombino y Banco O'Higgins, Santiago.

— 1993. Identidad y prestigio en los Andes: Gorros, turbantes y diademas. Museo Chileno de Arte Precolombino y Banco O’Higgins, Santiago.

OAKLAND, A., 1992. Textiles and ethnicity: Tiwanaku in San Pedro de Atacama, North Chile. Latin American Antiquity (3) 4: 316-340.

OYARZUN, A., 1931. Tejidos de Calama. En: Estudios Antropológicos y Arqueológicos, M. Orellana (Comp.). Editorial Universitaria, Santiago, 1979.

PELISSERO, N., C. FORGIONE y R. ALANCAY, 1997. El Pucara de Tilcara. Colección Mankacén, Buenos Aires.

RENARD, S. 1997. Objetos textiles, pasos y caminantes trasandinos. Piezas similares y rasgos comunes en textiles arqueológicos de Argentina y Chile. Estudios Atacameños 14: 291-306, San Pedro de Atacama.

REVISTA DEL C.I.A.D.A.M. (Centro de Investigaciones Arqueológicas de Alta Montaña), 1978. Antecedentes de Santuarios de Altura conocidos hasta Junio de 1978. Tomo 3: 50-71, San Juan.

ROLANDI DE PERROT, D., 1973. Los textiles tastileños. En: TASTIL. Una ciudad preincaica argentina. Cap. VI. Inv. Prehistórica de la División Antropología de la Facultad de Ciencias Naturales y Museo de la Universidad Nacional de la Plata. Ediciones Cabargón, Buenos Aires.

— 1979. Los tejidos de río Doncellas, Depto. de Cochinoca, Provincia de Jujuy. Actas de las Jornadas de Arqueología del Noroeste Argentino, pp.: 22-72, Facultad de Historia y Letras, Universidad del Salvador, Buenos Aires. 
ROWE, A. P. 1978. Technical features of Inca tapestry tunics. The Textile Museum Journal 17: 5-28, Washington D.C.

-1995-1996. Inca weaving and costume. The Textile Museum Journal, vol. 34-35: 4-53, Washington D.C.

SCHIAPPACASSE, V., V. CASTRO y H. NIEMEYER, 1989. Los Desarrollos Regionales en el Norte Grande. En $\mathrm{Cul}$ turas de Chile. Prehistoria. J. Hidalgo et al. (Eds.)., pp. 181-220. Editorial Andrés Bello, Santiago.
TARRAGO, M., 1989. Contribución al conocimiento arqueológico de las poblaciones de los oasis de San Pedro de Atacama en relación con los otros pueblos puneños, en especial, el sector septentrional del valle Calchaquí. Tesis para optar al Título de Doctor en Historia, especialidad Antropología. Universidad Nacional de Rosario, Facultad de Humanidades y Artes, Argentina.

URIBE, M. y C. AGÜERO, 2000. Alfarería, textiles y la integración del norte de Chile a Tiwanaku. Boletín de Arqueología PUCP (Pontificia Universidad Católica del Perú), Lima. En prensa. 